\title{
Hypothalamic regulation of pancreatic secretion is mediated by central cholinergic pathways in the rat
}

\author{
Ying Li, Xiaoyin Wu, Jinxia Zhu, Jin Yan and Chung Owyang \\ Gastroenterology Research Unit, Department of Internal Medicine, University of Michigan Health System, Ann Arbor, MI 48109, USA
}

\begin{abstract}
The vago-vagal reflex plays an important role in mediating pancreatic secretion evoked by cholecystokinin and non-cholecystokinin-dependent luminal factors. We hypothesize that the vago-vagal reflex mediating pancreatic secretion in the rat is under central control and regulated by cholinergic pathways in the hypothalamus. To test this hypothesis, we demonstrated that chronic decerebration decreased basal pancreatic enzyme secretion from $318 \pm 12$ to $233 \pm 9 \mathrm{mg} \mathrm{h}^{-1}$ and reduced the net increase in pancreatic secretion stimulated by intraduodenal infusion of $5 \%$ peptone and hypertonic $\mathrm{NaCl}$ by $54 \%$ and $45 \%$, respectively. Intracerebroventricular administration of methscopolamine (MSCP, $\left.50 \mathrm{nmol}(5 \mu \mathrm{l})^{-1}\right)$, a blood-brain barrier-impermeant cholinergic muscarinic receptor antagonist, evoked results similar to those achieved by chronic decerebration. To localize the sites of action, we demonstrated that microinjection of MSCP $(20 \mathrm{nmol})$ into the lateral hypothalamic nucleus or the paraventricular nucleus resulted in inhibition of both basal pancreatic protein secretion and luminally stimulated pancreatic secretion by $48 \%$ and $52 \%$, respectively. Intracerebroventricular injection of hemicholinium-3 at doses known to deplete the endogenous ACh store produced similar inhibitory results. In addition, microinjection of $\mathrm{ACh}(5 \mathrm{pmol})$ or the muscarinic $\mathrm{M}_{1}$ receptor agonist McN-A-343 (30 ng) into the lateral hypothalamic nucleus increased pancreatic secretion over basal levels by $46 \%$ and $40 \%$, respectively. Selective lesions of lateral septal cholinergic neurons decreased basal pancreatic secretion and inhibited peptone-induced pancreatic secretion by $30 \%$. Destruction of the lateral parabrachial nucleus produced a $44 \%$ inhibition of peptone-induced pancreatic section. Finally, microinjection of glutamate into the lateral septum or the lateral parabrachial nucleus stimulated vagal pancreatic efferent nerve firings from a basal level of $0 \pm 0.5$ impulses $(30 \mathrm{~s})^{-1}$ to $4.5 \pm 0.5$ and $14 \pm 2$ impulses $(30 \mathrm{~s})^{-1}$, respectively, and pancreatic protein output increased $50 \%$ and $84 \%$ over basal levels. Administration of MSCP to the paraventricular nucleus eliminated these effects. These observations suggest that cholinergic neurons of the lateral septum and lateral parabrachial nucleus regulate pancreatic secretion. Further, cholinergic input from the lateral parabrachial nucleus to the hypothalamus plays a major role in the modulation of vagal pancreatic efferent nerve activity and pancreatic secretion evoked by the vago-vagal reflex.
\end{abstract}

(Resubmitted 11 June 2003; accepted after revision 7 August 2003; first published online 8 August 2003)

Corresponding author Y. Li: Division of Gastroenterology, University of Michigan, 6510 Medical Sciences Research Building I, 1150 West Medical Center Drive, Ann Arbor, Ml 48109-0682, USA. Email: yli@umich.edu

Exocrine pancreatic secretion is largely controlled by the autonomic nervous system. We and other investigators have clearly demonstrated that the vago-vagal reflex plays a crucial role in the mediation of postprandial pancreatic enzyme secretion. Previous studies in the rat showed that cholecystokinin (CCK) (Li \& Owyang, 1993b, 1994; Li et al. 1997) and luminal non-CCK-dependent factors (Li \& Owyang, 1996b) such as osmolality, disaccharides, and mechanical stimulation evoke pancreatic secretion via intestinal vagal mucosal afferent fibres. We recently demonstrated that 5-HT released from intestinal enterochromaffin cells acts as a paracrine substance to mediate luminal non-CCK-stimulated pancreatic secretion (Li et al. 2000). Although pancreatic secretion can be mediated by vago-vagal reflexes located within the brainstem, these reflexes may be modulated by input from higher centres (Rogers et al. 1996).

It has been recognized since Pavlov's time (Pavlov, 1910) that the CNS exerts considerable control over the cephalic phase of pancreatic secretion (Sarles et al. 1968). The hypothalamus receives a wide variety of convergent afferent inputs from the viscera and regulates autonomic activities by modulating neuronal input to autonomic preganglionic neurons. With the exception of the pioneering work of Gilsdorf et al. (1966), which suggested the involvement of the hypothalamus in regulating pancreatic secretion, the physiological significance of forebrain input in the 
mediation of postprandial pancreatic secretion has remained largely unexplored.

Muscarinic receptors are widely distributed in the brain, including the hypothalamus and the vagal nucleus, and central muscarinic actions are potentially widespread (Whittaker, 1988). Previous studies have shown that the central cholinergic pathway contributes significantly to the regulation of digestive functions, including salivation (Tomic-Beleslin \& Beleslin, 1986), gastric secretion (Grill \& Norgren, 1978), gastric dysrhythmias (Hasler et al. 1995), emesis (Pedigo \& Brizzee, 1985), and the oesophagomotor response (Lu \& Bieger, 1998). Endocrine pancreatic polypeptide (PP) cells within the pancreatic islets and scattered throughout the exocrine tissue synthesize and release PP (Taylor, 1989). The plasma PP response is a reliable index of vagal cholinergic input to the pancreas. Infusion of atropine into the lateral cerebral ventricle is known to abolish fluctuations of basal PP levels and also PP secretion stimulated by hypoglycaemia or food intake (Okita et al. 1997), which suggests involvement of the central muscarinic cholinergic system in the regulation of vagal efferent input to the pancreas.

We have shown that peripheral cholinergic blockade completely abolishes pancreatic secretion (Li \& Owyang, $1993 b, 1994)$. The role of central cholinergic neurons in the regulation of pancreatic secretion, however, is unknown. Choline acetyltransferase immunoreactivity is abundant in the CNS, including the septal nuclei, parabrachial nucleus (PBN), bed nucleus, amygdala, and hypothalamus (Ruggiero et al. 1990). We hypothesize that involvement of the vago-vagal reflex in mediating pancreatic secretion is under central control and regulated by cholinergic pathways in the hypothalamus. In this study, we performed in vivo pancreatic secretion studies in the conscious rat and investigated the effects of chronic decerebration on basal and stimulated pancreatic enzyme secretion. To localize the sites of action, we examined the effects of microinjection of methscopolamine (MSCP) into the dorsal motor nucleus of the vagus (DMV), the lateral hypothalamic nucleus (LH) and the paraventricular nucleus (PVN) on pancreatic secretion evoked by luminal stimuli. In addition, we investigated the role of endogenous ACh on basal and stimulated pancreatic secretion by administration of intracerebroventricular (I.C.V.) injections of hemicholinium-3 at doses known to deplete the endogenous ACh store. To identify the sites of cholinergic neurons responsible for modulating pancreatic secretion, we examined the effects of selective destruction of cholinerginc neurons on pancreatic secretion: immunotoxin 192 IgG-saporininduced lesion of the cholinergic basal forebrain neurons and ibotenic acid-induced lesion of the PBN. To determine if lateral septal or lateral PBN (LPBN) stimulation activates the vagal pancreatic efferent nerve, electrophysiological activity of the vagal pancreatic nerve was recorded.

\section{METHODS}

\section{Materials}

Peptone, (-)scopolamine methyl nitrate (MSCP), hemicholinium3 , and McN-A-343 were purchased from Sigma-Aldrich (St Louis, MO, USA). Ibotenic acid was obtained from Research Biochemicals International (Natick, MA, USA). 192 IgG-saporin was purchased from CHEMICON International, (Temecula, CA, USA).

\section{Animal preparation}

All protocols used in this study were approved by the University Committee on Use and Care of Animals at the University of Michigan. After an overnight fast, male Sprague-Dawley rats weighing 250-300 g were anaesthetized with a mixture of xylazine and ketamine (13 and $87 \mathrm{mg}$ ( $\mathrm{kg}$ body weight $)^{-1}$, respectively, I.M.). One-third of the initial anaesthetic dose was given every 90 min thereafter to maintain surgical anaesthesia. This anaesthetic procedure was used to prepare rats for all studies described, including chronic decerebration, brain cannulation, brain nuclei lesion, and re-anaesthetization of the rats for pancreatic efferent nerve recording. At the end of each experiment, the rats were killed with a barbiturate overdose (70 $\mathrm{mg} \mathrm{kg}^{-1}$, I.V.).

Chronic decerebration. To quantify pancreatic secretion contributed by the rat forebrain, we performed chronic decerebration, a classical method designed to remove the influence of the forebrain. The procedure involves placing the rat in a stereotaxic frame, removing the dura, and then transecting the brain at the supracollicular level in a two-stage procedure using a handheld spatula (Grill \& Norgren, 1978; DiRocco \& Grill, 1979). Chloramphenicol (1\% solution) was applied to the exposed scalp prior to closure to limit local infection. Completeness of the transection was verified histologically in all cases.

Nursing care. The decerebrate rats were incapable of effective thermoregulation or spontaneous feeding or drinking, but they were capable of consuming orally administered fluids (Steiner, 1973). Body temperature was maintained between $34^{\circ} \mathrm{C}$ and $37.5^{\circ} \mathrm{C}$ by warming or evaporative cooling. Rectal temperature was recorded 3 times daily. The decerebrate rats and the controls were tube fed three $12-\mathrm{ml}$ meals daily consisting of equal parts sweetened condensed milk and water (with a multiple vitamin supplement). The animals were housed individually and subjected to a 12-h day: 12 -h night cycle. Pancreatic secretion studies were performed 7-10 days after decerebration.

Intracerebroventricular cannulation. The animal was placed in a stereotaxic unit with the upper incisor bar placed $3 \mathrm{~mm}$ above the interaural line. A small hole was drilled into the skull, through which a $15-\mathrm{mm}$-long stainless steel cannula (24 gauge) was introduced perpendicularly into the middle of the left cerebral ventricle. The cannula was secured with two screws inserted into the surface of the parietal bone and fixed with cranioplastic powder (Plastics One). Coordinates from the bregma were as follows: anteroposterior, $0.6 \mathrm{~mm}$; lateral, $2 \mathrm{~mm}$; and ventral, $4 \mathrm{~mm}$.

DMV cannulation. Brain nuclei microinjection in conscious rats was accomplished by implanting a unilateral guide cannula into the DMV using an adaptation of a technique described by Michelini \& Bonagamba (1988) and Callera et al. (1997). A small window was opened caudal to the lambda, through which a 15mm-long stainless steel cannula (24 gauge) was introduced perpendicularly, $14 \mathrm{~mm}$ caudal to the bregma, $0.5 \mathrm{~mm}$ lateral to 
the midline, $8.3 \mathrm{~mm}$ below the skull surface. The guide cannula was fixed to the skull with methacrylate and watch screws and closed with an occluder until the time of experimentation. The 33-gauge needle used to administer microinjections into the DMV measured $1.5 \mathrm{~mm}$ longer than the guide cannula and was connected by polyethylene tubing to a microinfusion pump for intracranial drug delivery.

Hypothalamic nuclei cannulation. The guide cannula was introduced into the hypothalamic region at the following coordinates: LH: $2.2-2.8 \mathrm{~mm}$ posterior, $1.6-1.9 \mathrm{~mm}$ lateral, 7.2-7.8 mm below the skull surface; PVN: $1.8 \mathrm{~mm}$ posterior to the bregma, $0.8 \mathrm{~mm}$ lateral to the midline, and $8.0 \mathrm{~mm}$ below the skull surface. For the control treatment, the cannula was inserted in the vicinity of the PVN and LH but outside their borders.

After 3-4 days, pancreatic enzyme secretion studies were performed in conscious rats. We observed that brain nucleus cannulation did not alter feeding and drinking behaviour and the rats gained an average of $6.1 \mathrm{~g}$ in 7 days.

Septal nuclei and LPBN cannulation. To perform septal nuclei and LPBN microinjection during electrophysiological recording of vagal pancreatic efferent nerve, unilateral guide cannulas were inserted at the following coordinates: lateral septal nucleus (LS): $1.0 \mathrm{~mm}$ rostral to the bregma, $0.8 \mathrm{~mm}$ lateral to the midline, and $5.7 \mathrm{~mm}$ below the skull surface; the lateral PBN: $9.4 \mathrm{~mm}$ caudal to the bregma, $2.2 \mathrm{~mm}$ lateral to the midline and $4.1 \mathrm{~mm}$ below the skull surface. On completion of each experiment the rats were killed with a barbiturate overdose $\left(70 \mathrm{mg} \mathrm{kg}^{-1}\right.$, I.V.). The brain was removed and fixed in a formalin-20\% sucrose solution for 2 days. Serial coronal sections $(30 \mu \mathrm{m})$ were cut, stained by the Nissl method, and examined microscopically. The location of the microinjection was determined to be the point of termination of the cannula track and marked on the plates reproduced from the atlas of the rat brain by Paxinos \& Watson (1998).

Immunotoxic lesions of cholinergic neurons by 192 IgGsaporin. Wiley et al. (1992) developed an excellent tool for selectively lesioning cholinergic basal forebrain neurons. Previous studies have shown that injection of 192 IgG-saporin (10 ng) into the nucleus basalis magnocellularis (NBM) provided the greatest loss of cholinergic cells that project to the cortex, without loss of hippocampal afferents and with limited loss of striatal cholinergic cells (Wenk et al. 1994). Injection of 192 IgG-saporin at a dose of $0.22 \mu \mathrm{g}$ into the medial septum (MS) resulted in no apparent loss of parvalbumin, a calcium-binding protein that serves as a marker for GABAergic projection neurons in the MS (Johnson et al. 2002), which suggests the selective destruction of cholinergic neurons. In the current study, we used $192 \mathrm{IgG}$-saporin (10 ng in $0.03 \mu \mathrm{l}$ ) in sterile PBS, a concentration known to induce the greatest loss of cholinergic cells (Wenk et al. 1994). A micropipette tip (outside diameter $40-60 \mu \mathrm{m}$ ) was placed in the MS (coordinates: $0.45 \mathrm{~mm}$ anterior and $0.2 \mathrm{~mm}$ lateral to the bregma, and $5.7 \mathrm{~mm}$ below the skull surface), the lateral septum (LS) ( $1.0 \mathrm{~mm}$ anterior and $0.8 \mathrm{~mm}$ lateral to the bregma, and $5.7 \mathrm{~mm}$ below the skull surface), and the NBM $(0.9 \mathrm{~mm}$ posterior to the bregma, $2.8 \mathrm{~mm}$ lateral to the midline, and $7 \mathrm{~mm}$ below the skull surface). A $0.03 \mu \mathrm{l}$ solution was delivered for $2 \mathrm{~min}$ at each site.

The lesioned animals generally took longer to recover from the effects of the anaesthetic than the sham-lesioned controls. They appeared more lethargic and were less inclined to eat or drink after surgery. Postoperative weight loss was universal, but 3 days after surgery, sham- and MS-, LS-, NBM-cholinergic ablated animals showed a daily weight gain. Experimentation began on the 10th postoperative day.

Immunohistochemistry. After pancreatic secretion studies, at least two rats from each group were used for histological studies. The rats were deeply anaesthetized with sodium pentobarbital $\left(100 \mathrm{mg} \mathrm{kg}^{-1}\right)$ and perfused transcardially with saline followed by $10 \%$ formalin. The brain was quickly removed. Serial coronal sections $(40 \mu \mathrm{m})$ were cut through the basal forebrain. The sections were incubated in polyclonal mouse anti-choline acetyltransferase (MAB 305, 1:600, CHEMICON International, Temecula, CA, USA) in PBS-TX containing $0.1 \%$ BSA (PBSTX-BSA) for $12 \mathrm{~h}$ at $4^{\circ} \mathrm{C}$. The specimens were rinsed three times with PBS-TX-BSA, then incubated for $60 \mathrm{~min}$ at $35^{\circ} \mathrm{C}$ with a secondary antibody (donkey-mouse Cy3) (1:200) in PBSTX-BSA. The specimens were examined with a fluorescence microscope (Nikon Optiphot-2) using appropriate excitation wavelengths $(550-570 \mathrm{~nm})$. One set from each of the brains was counterstained with neutral red to facilitate identification of the neurons. Brain tissue from unoperated rats was processed in parallel as a positive control.

Ibotenic acid lesions of the PBN. Cholinergic neurons in the parabrachial nucleus send direct input to the hypothalamic nuclei, including the LH and PVN (Saper \& Loewy, 1980). PBN cholinergic neurons do not display nerve growth factor receptor (NGFr) staining and are unaffected by 192 IgG-saporin injections (Heckers et al. 1994). In this study, we used the neurotoxin ibotenic acid to lesion the PBN. It has been shown in rodents that viscerosensory neurons are located in the LPBN (Fulwiler \& Saper, 1984; Herbert et al. 1990), and the gustatory responsive neurons are found in the medial subdivisions of the PBN (MPBN) (Halsell \& Frank, 1991). After a scalp incision, two holes were drilled into the skull to provide access to the bilateral LPBN at the following coordinates: $9.4 \mathrm{~mm}$ caudal to the bregma, $2.2 \mathrm{~mm}$ lateral to the midline, and $6 \mathrm{~mm}$ below the surface of the skull. Access to the MPBN was achieved at the following coordinates: $11.5 \mathrm{~mm}$ posterior to the bregma and $1.0-1.5 \mathrm{~mm}$ lateral to the midline. A micropipette was back-filled with ibotenic acid immediately prior to injection; a $0.15-\mu \mathrm{l}$ dose $\left(20 \mu \mathrm{g} \mu \mathrm{l}^{-1}\right)$ was infused over $10 \mathrm{~min}$. To minimize spread of the neurotoxin along the track, the micropipette remained in situ for an additional $10 \mathrm{~min}$ before the procedure was repeated on the contralateral site. At the completion of the surgical procedure, the scalp incision was closed with wound clips. The experiment was started after 3 weeks' postoperative recovery.

Histology. Serial coronal sections $(50 \mu \mathrm{m})$ were cut at on a cryostat, mounted on gelatin-coated slides, and stained with cresyl violet. The extent of the lesions was determined by examining the sections under a light microscope, and reconstructions were made on charts derived from the atlas of Paxinos \& Watson (1998).

\section{Postoperative care}

Sterile isotonic saline (10 ml, subcutaneous) was administered to prevent dehydration during recovery, and bicillin $(0.5 \mathrm{ml}$, $300000 \mathrm{U} \mathrm{ml}^{-1}$, intramuscular) to prevent infection. On completion of surgery, rats were placed on a warm recovery pad and their general condition was monitored. After recovery from the anaesthesia, the rats were returned to the animal quarters and their body weight and general behaviour were monitored daily. Lidocaine (lignocaine) was applied locally to the scalp to reduce discomfort. Diluted Tylenol (50 $\mathrm{mg} \mathrm{kg}^{-1}$, cherry flavoured) was available for $24 \mathrm{~h}$ after surgery. 
Pancreatic secretion studies in conscious rats. For the physiological studies, we used a conscious rat model in which a chronic pancreatic and duodenal catheter was passed through a modified plastic housing (Li et al. 1997) sutured to the abdominal ventral wall. One end of the tubing (PE-10 or PE-50, Clay-Adams, Becton, Dickinson and Company, Sparks, MD, USA) was inserted into the common bile-pancreatic duct, and the other end was placed in the duodenum through a cannula (PE 60 or PE 190) fixed in the housing. After surgery, the animals were returned to a regular cage for 4 days to recover until the experiments were performed. During the experiment, the pancreatic catheter was gently disconnected from the duodenal cannula for the collection of bile-pancreatic juice.

After a 30-min stabilization period, combined biliary-pancreatic secretions were collected every $15 \mathrm{~min}$. The volume was measured and an aliquot was taken and diluted with distilled water for protein determination. The remaining undiluted bile-pancreatic juice was pumped back into the rat through the duodenal cannula during the next collection period at the secretion rate of the preceding collection period. Protein in the bile-pancreatic juice was measured spectrophotometrically using the assay method of Bradford (Li et al. 2000). In a previous study, we confirmed that the increase in protein output in the bile-pancreatic juice after CCK-8 and non-CCK luminal stimulation (authors' unpublished observations) reflected protein from the pancreatic source. Biliary juice protein did not increase in response to CCK stimulation.

Duodenal perfusion studies. Previous research (Li et al. 1996b) showed that pancreatic secretion in response to intraduodenal perfusion of peptone is mediated by endogenously released CCK. We have also shown that intestinal 5-HT released from enterochromaffin cells mediates pancreatic secretion stimulated by luminal hypertonic $\mathrm{NaCl}$ solution (Li et al. 2000). Both CCK and 5-HT act via stimulation of vagal afferent pathways to evoke pancreatic secretion. In the present study these methods were used to examine the role of the CNS in mediating pancreatic secretion evoked by the vago-vagal reflex. After a 45 -min basal period, $5 \%$ peptone or hypertonic $\mathrm{NaCl}\left(600 \mathrm{mosmol}^{-1}\right)$ was perfused into the duodenum at a constant rate of $3 \mathrm{ml} \mathrm{h}^{-1}$ by a peristaltic pump. The vehicle and two test solutions were administrated separately in random order, each for $75 \mathrm{~min}$, with a 45-min resting period between each test to allow pancreatic secretion to return to basal level. In the first group of rats prepared with I.C.V. cannulas, after a 30-min basal collection of bile-pancreatic juice, I.C.V. infusion of vehicle solution $(6 \mu \mathrm{l})$ was followed by intraduodenal infusion of peptone and hypertonic $\mathrm{NaCl}$. The next day, the same rats received an I.C.v. infusion of the blood-brain barrier-impermeant cholinergic muscarinic receptor antagonist MSCP (5 or $\left.50 \mathrm{nmol}(6 \mu \mathrm{l})^{-1}\right)$. To determine if endogenous acetylcholine plays a physiological role in the mediation of pancreatic secretion, we examined the effects of I.C.V. infusion of hemicholinium-3 (20 $\mu \mathrm{g}$ in 6-8 $\mu \mathrm{l}$, dissolved in saline, delivered over $1 \mathrm{~min}$ ) in a separate group of rats, The internal cannula was kept in position for $45 \mathrm{~s}$ before being retracted. Pancreatic secretion studies were performed. Immediately before killing the rats, $2 \mu \mathrm{l}$ of methylene blue was administered by I.C.V. injection to verify the injection site. Data from animals that did not display the dye throughout the ventricular system were excluded from analysis. To localize the sites of action of MSCP, we performed brain nucleus microinjection studies. In separate groups of rats prepared with DMV, LH, or PVN cannulas, vehicle or MSCP $\left(40 \mathrm{nl}(15 \mathrm{~s})^{-1}\right)$ was delivered by a microinjector (David Kopf Instruments, Tujunga, CA, USA).
Intraduodenal perfusion studies were performed after the injection.

Pancreatic secretion studies were also conducted in rats 10 days after septal nuclei and NBM cholinergic lesion by 192 IgGsaporin, and in rats 3 weeks after PBN lesion by ibotenic acid. In the another series of experiments, after a 30 -min basal collection, vehicle or ACh (5 pmol) or the muscarinic $\mathrm{M}_{1}$ receptor agonist McN-A-343 (20 pmol) was microinjected into the DMV, LH, and PVN, and pancreatic secretion studies were performed.

On completion of each experiment, minimal changes were observed in the animals' general behaviour, such as locomotor activity, grooming, and rearing to the side or in the centre of the cage, suggesting that microinjection of various agents did not cause distress.

\section{Electrophysiological recording of vagal pancreatic efferent nerve}

After 5 days of recovery, the rats prepared with LPBN or LS cannulas were re-anaesthetized, and prepared with a tracheal tube that permitted artificial ventilation with room air. Body temperature was maintained with a special heating pad. The pancreatic nerve of the vagus running along the side of the splenic artery was isolated from the central cut end, and efferent nerve activity was recorded using bipolar platinum electrodes. A strip of connective tissue was wrapped around the second indifferent electrode. Multi-unit efferent recordings were thus obtained from the vagal pancreatic nerve. The electrophysiological signal was amplified by an A-M system, high-input impedance that was preamplified and monitored with an oscilloscope and audio monitor. The discharges were displayed and stored electronically using Axon tape software (Axon Instruments) and a $166-\mathrm{MHz}$ Pentium processor for off-line computer analysis. After $5 \mathrm{~min}$ of recording the vagal pancreatic nerve firings to confirm the stability of the firing frequency, basal discharge was monitored for $5 \mathrm{~min}$. Discharge frequency after microinjection of glutamate $\left(30 \mathrm{nmol}(50 \mathrm{nl})^{-1}\right)$ into the LPBN was measured over $20 \mathrm{~min}$. At the completion of the electrophysiological study, the same rats were subjected to the pancreatic secretion study in response to glutamate injection into the LPBN.

At the end of each experiment, the rats were killed with a barbiturate overdose ( $70 \mathrm{mg} \mathrm{kg}^{-1}$, I.V.). The brain was removed, and stored in formalin-20\% sucrose solution for 2 days, and serial coronal sections $(20 \mu \mathrm{m})$ were cut and stained by the Nissl method. Histological sections were examined microscopically. The location of the microinjection site was determined to be the point of termination of the cannula track and was marked on the plates reproduced from the rat brain atlas of Paxinos \& Watson (1998).

Data analysis. Off-line single-unit analyses were performed using the Datapac software system 2000 (Run Technologies, Laguna Hills, CA, USA), and the spike sorting module software (Li et al. 1999). Time histograms were constructed for all final $30 \mathrm{~s}$ recordings. The basal discharge frequency and the stimulusinduced discharge frequency were determined by calculating the average volume of all $30 \mathrm{~s}$ periods in $3 \mathrm{~min}$. The results were compared with those obtained after I.C.V. injection of MCSP.

\section{Statistical analysis}

Results were expressed as means \pm S.E.M. Multivariate ANOVA was used to evaluate the effects of repeated measurements over time, the effects of treatment, and the interaction between these two variables. Basal output was determined to be the average of 
two 15-min periods. The cumulative net increase in protein output was calculated as the sum of protein output during the final 30 min of intestinal infusion of peptone or hypertonic $\mathrm{NaCl}$ minus the basal output. Zero cumulative output was considered to reflect $100 \%$ inhibition. Subsequent comparisons were made with the Newman-Keuls test (InStat Biostatistics 2.01. Graphpad Software, Inc.).

\section{RESULTS}

\section{Effects of chronic decerebration on pancreatic secretion in conscious rats}

The chronically decerebrate rats were sufficiently coordinated to groom their fur. Although they exhibited relative immobility, they often overreacted with wellcoordinated movements such as running and jumping (Tang, 1955). Previous studies have shown that chronically decerebrate rats retain the capacity to increase plasma glucose concentration in response to 2-deoxyglucose (DiRocco \& Grill, 1979). In this study, both shamoperated $(n=4)$ and decerebrate rats $(n=6)$ showed a weight gain: $245 \pm 6 \mathrm{~g}$ (sham-operated) and $248 \pm 8 \mathrm{~g}$ (decerebrate) before surgery to $262 \pm 6$ and $260 \pm 10 \mathrm{~g}$ on the 10th day after surgery. Basal pancreatic secretion rates averaged $318 \pm 12 \mathrm{mg} \mathrm{h}^{-1}$ in conscious rats. Duodenal infusion of $5 \%$ peptone or hypertonic $\mathrm{NaCl}$ at $3 \mathrm{ml} \mathrm{h}^{-1}$ increased protein secretion in sham-operated rats to $588 \pm 9$ and $569 \pm 13 \mathrm{ml} \mathrm{h}^{-1}$, respectively, an $85 \%$ and $79 \%$ increase in protein output over basal (Fig. $1 A$ and $B$ ). The cumulative net increases in protein output were $130 \pm 15$ and $122 \pm 12 \mathrm{mg}(30 \mathrm{~min})^{-1}$, respectively. Chronic decerebration caused a reduction in basal pancreatic protein output to $233 \pm 9 \mathrm{mg} \mathrm{h}^{-1}$. In response to duodenal infusion of $5 \%$ peptone or hypertonic $\mathrm{NaCl}$, the pancreatic protein output in decerebrate rats increased to $354 \pm 11$ and $301 \pm 14 \mathrm{mg} \mathrm{h}^{-1}$, respectively, representing $50 \%$ and $36 \%$ increases over basal (Fig. $1 A$ and $B$ ). The cumulative net increases in protein output were $60 \pm 7$ and $50 \pm 9 \mathrm{mg}(30 \mathrm{~min})^{-1}$, respectively (Fig. 1C). Thus, compared to controls, chronic decerebration resulted in $46 \%$ and $40 \%$ less pancreatic protein secretion in response to luminal perfusion of, respectively, peptone and hypertonic $\mathrm{NaCl}$.

\section{Effects of I.C.V. administration of MSCP on pancreatic secretion stimulated by peptone and hypertonic $\mathrm{NaCl}$}

An I.C.V. injection of $5 \mathrm{nmol}$ MSCP had no effect on basal pancreatic protein output, whereas a dose of $50 \mathrm{nmol}$ decreased basal pancreatic protein output from 320 to $210 \mathrm{mg} \mathrm{h}^{-1}$ (Fig. 2A). I.C.V. infusion of MSCP produced a partial inhibition of pancreatic secretion stimulated by luminal peptone and hypertonic $\mathrm{NaCl}$ (Fig. 2B). The cumulative net increases in protein output were $70 \pm 6 \mathrm{mg}(30 \mathrm{~min})^{-1}$ after infusion of peptone, and $57 \pm 4 \mathrm{mg}(30 \mathrm{~min})^{-1}$ after infusion of hypertonic $\mathrm{NaCl}$ (Fig. $2 B$ and $C$ ). Compared to controls, these results represent a $47 \%$ and $56 \%$ reduction in response to, respectively, intestinal peptone and hypertonic $\mathrm{NaCl}$ stimulation.

\section{Effects of microinjection of MSCP into the LH on basal and pancreatic secretion in response to luminal stimulation in conscious rats}

Bilateral LH injection of MSCP at a dose of $5 \mathrm{nmol}$ resulted in a significant decrease of basal pancreatic secretion from
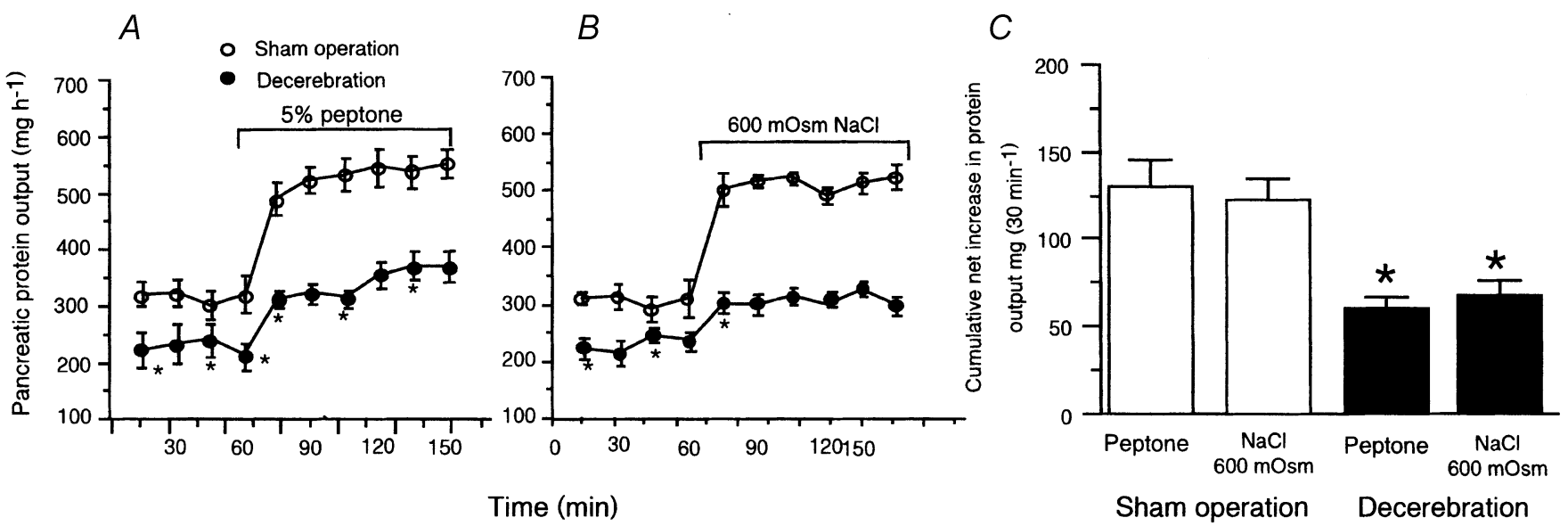

Figure 1. Effects of chronic decerebration on pancreatic secretion in conscious rats

Chronic decerebration induced a decrease in basal pancreatic enzyme secretion from $318 \pm 12$ to $233 \pm 9 \mathrm{mg} \mathrm{h}^{-1}$ and a reduction in pancreatic secretion stimulated by intraduodenal infusion of $5 \%$ peptone $(A)$ and hypertonic $\mathrm{NaCl}(B)$ by $54 \%$ and $45 \%$, respectively. $C$, cumulative net increase in pancreatic protein output (i.e. the sum of protein output during the final $30 \mathrm{~min}$ of intestinal infusion of peptone or hypertonic $\mathrm{NaCl}$ minus basal output in sham-operated and decerebrate rats). These observations indicate that the forebrain plays an important role in maintaining basal pancreatic secretion and in modulating vagal afferentstimulated pancreatic secretion. Values are means \pm S.E.M. for 4 sham-operated and 6 decerebrate rats. ${ }^{*} P<0.05$ compared with sham operation. 


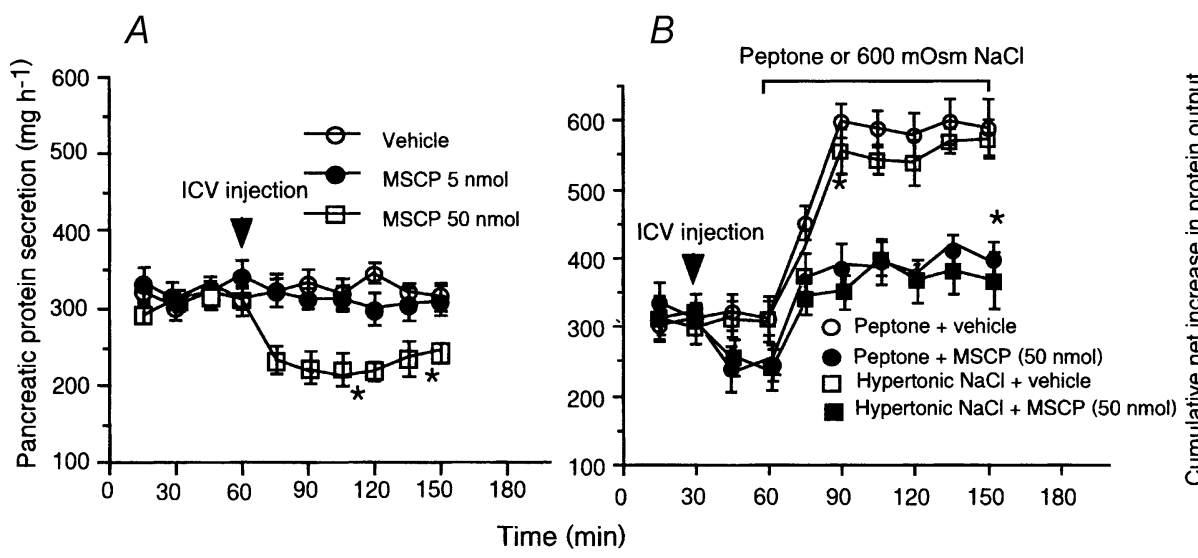

C

Figure 2. Effects of intracerebroventricular administration of the cholinergic antagonist methscopolamine on pancreatic secretion in conscious rats

$A$, intracerebroventricular (I.C.V.) administration of methscopolamine (MSCP) at a dose of $5 \mathrm{nmol}$ had no effect on basal pancreatic protein output, whereas a 50 -nmol dose induced a decrease in basal pancreatic protein output from 320to $210 \mathrm{mg} \mathrm{h}^{-1}$. B, intraduodenal infusion of peptone and hypertonic $\mathrm{NaCl}$ increased protein secretion by $100 \%$ and $70 \%$, respectively. We have previously shown that these responses are mediated by a vagal mucosal afferent pathway. I.C.V. MSCP administration partially inhibited pancreatic protein output stimulated by peptone or hypertonic $\mathrm{NaCl}$. C, cumulative net increase in pancreatic protein output in response to intraluminal peptone or hypertonic $\mathrm{NaCl}$ was significantly reduced in decerebrate rats compared to controls. Values are means \pm s.E.M. for 4 rats in each group. ${ }^{\star} P<0.05$ compared with sham operation.

$320 \pm 11$ to $219 \pm 17 \mathrm{mg} \mathrm{h}^{-1} \quad(n=4)$ (Fig. $\left.3 A\right)$. The inhibitory effect lasted $60 \mathrm{~min}$. This observation indicates that cholinergic tone in the hypothalamus regulates basal pancreatic secretion. Bilateral microinjection of MSCP into the $\mathrm{LH}$ reduced the cumulative net increase in protein output in response to duodenal perfusion of peptone from $120 \pm 6$ to $71 \pm 8 \mathrm{mg}(30 \mathrm{~min})^{-1}$ (Fig. $3 B$ and $C$ ). Injection of
MSCP near but outside the LH, specifically into the magnocellular preoptic nuclei $(n=1)$ and the anterior hypothalamic area $(n=1)$ did not affect the pancreatic protein secretion. These rats were excluded from the statistical analyses. These observations suggest that muscarinic cholinergic receptors in the $\mathrm{LH}$ are involved in regulating pancreatic secretion evoked by the vago-vagal reflex.
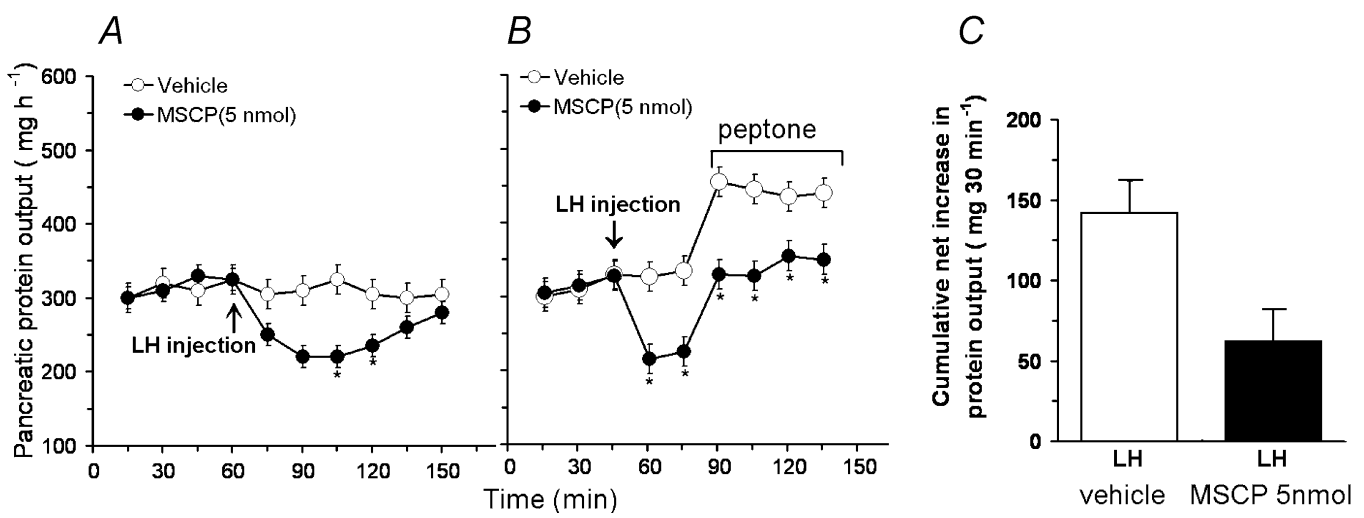

Figure 3. Effects of bilateral microinjection of methscopolamine into the lateral hypothalamic nucleus on pancreatic secretion in conscious rats

$A$, microinjection of methscopolamine (MSCP) into the lateral hypothalamic nucleus (LH) resulted in a significant decrease in unstimulated pancreatic secretion, indicating that basal cholinergic tone in the hypothalamus regulates basal pancreatic secretion. $B$, time course of peptone-induced pancreatic secretion in the presence and absence of MSCP. $C$, cumulative net increases in pancreatic protein output. MSCP injection into the LH significantly reduced basal pancreatic protein secretion and peptone-stimulated pancreatic protein secretion, suggesting that muscarinic cholinergic receptors in the hypothalamus are involved in mediating pancreatic secretion. Values are means \pm s.E.M. for 4 rats in each group. 


\section{Effects of microinjection of hemicholinium-3 into} the lateral cerebral ventricle on pancreatic secretion A decrease in basal protein output from $308 \pm 12$ to $220 \pm 7 \mathrm{mg} \mathrm{h}^{-1}$ (Fig. 4A) was observed $45 \mathrm{~min}$ after acute injection of hemicholinium-3 $(20 \mu \mathrm{g})$ into the lateral cerebral ventricle of unanaesthetized rats. This treatment also resulted in significant inhibition of luminally stimulated pancreatic secretion (Fig. 4B). The respective cumulative net increases in protein output were $70 \pm 5$ and $61 \pm 3 \mathrm{mg}(30 \mathrm{~min})^{-1}$ in response to intraduodenal peptone or hypertonic $\mathrm{NaCl}$ stimulation; reductions of $47 \%$ and $51 \%$ compared to controls (Fig. $4 C$ ).

Effects of microinjection of ACh into the LH, PVN, dorsomedial hypothalamic nucleus (DMH), and DMV on pancreatic secretion in conscious rats

Six rats were used for each nucleus injection study. Microinjection of ACh at a dose of 5 or 50 pmol into the DMH $(n=4)$ had no significant effect on pancreatic secretion (Fig. 5F). Similarly, ACh injection outside the $\mathrm{DMH}$ (perifornical nucleus and ventromedial hypothalamic nucleus) $(n=2)$ had no effect on pancreatic secretion. Microinjection of ACh at a dose of 5 pmol into the LH $(n=5)$ (Fig. $5 A)$ or PVN $(n=4)$ (Fig. $5 B)$ induced an increase in protein output from $318 \pm 12$ to $481 \pm 10$ and $475 \pm 7 \mathrm{mg} \mathrm{h}^{-1}$, respectively. The increase was observed after the 3-min injection and peaked within $15 \mathrm{~min}$. Microinjection of the $M_{1}$ muscarinic receptor agonist McN-A-343 (50 pmol) into the LH or PVN (Fig. 5C and $D$ ) mimicked the stimulatory effects of ACh on pancreatic secretion. Injection of ACh near, but outside the LH (i.e. anterior hypothalamic area), or outside of the PVN (i.e. reuniens nucleus or anterior hypothalamic area), did not cause a significant increase in pancreatic secretion. These observations indicate that stimulation of muscarinic receptors in the hypothalamus evokes pancreatic protein secretion. Microinjection sites in the hypothalamus are shown in Fig. 6. Previous studies in which a similar cannula injection technique was used showed that after microinjection of $\left[{ }^{3} \mathrm{H}\right]\left[3\right.$-methyl-His $\left.{ }^{2}\right]-\mathrm{TRH}(50 \mathrm{nl})$ into the preoptic nucleus more than $75 \%$ of the radioactivity was measured within a $600-\mu \mathrm{m}$ diameter of the injection site (Siren et al. 1991). Microinjection of ACh (5 or $50 \mathrm{pmol}$ ) into the DMV had no effect on pancreatic secretion $(n=4)$ (Fig. $5 E)$. In two rats, the injection sites were found near the border of the hypoglossal nucleus. No change in pancreatic secretion was observed.

\section{Effects of selective lesion of cholinergic neurons in the basal forebrain by 192 IgG-saporin}

Immunohistochemistry confirmed that areas of the MS (Fig. 7), LS, and NBM were nearly completely depleted of ChAT-immunopositive neurons. No tissue necrosis or nonspecific damage was observed. MS lesion and NBM lesion had no effect on either basal pancreatic protein secretion or pancreatic secretion stimulated by intraduodenal perfusion of peptone (Fig. $8 A$ ). In contrast, the LS lesion resulted in a decrease in basal protein output from $310 \pm 7$ to $212 \pm 7 \mathrm{mg} \mathrm{h}^{-1}$ (Fig. $8 A$ ), and reduced the cumulative net increases in protein output stimulated by peptone from a control rate of $118 \pm 6 \mathrm{mg}(30 \mathrm{~min})^{-1}$ to $80 \pm 4 \mathrm{mg}(30 \mathrm{~min})^{-1}$, representing a $30 \%$ inhibition (Fig. 8B). These observations suggest that cholinergic neurons in the LS are involved in modulating pancreatic tone and protein secretion evoked by the vago-vagal reflex.
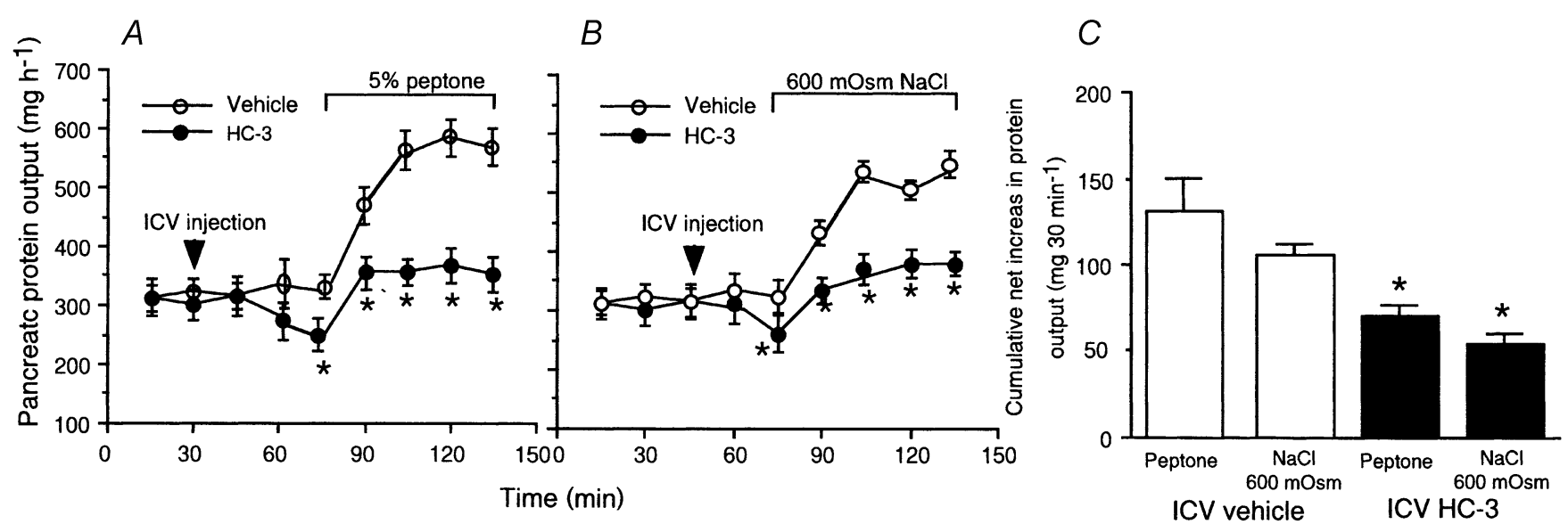

\section{Figure 4. Effects of microinjection of hemicholinium-3 into the lateral cerebral ventricle on} pancreatic secretion in conscious rats

Acute injection of hemicholinium-3 (HC-3, $20 \mu \mathrm{g}$ ) into the lateral cerebral ventricle of unanaesthetized rats induced a decrease both in basal pancreatic secretion and in pancreatic secretion stimulated by intraduodenal perfusion of peptone $(A)$ and hypertonic saline $(B) . C$, cumulative net increase in pancreatic protein output in response to intraluminal peptone or hypertonic $\mathrm{NaCl}$ was significantly reduced after $\mathrm{HC}-3$ administration. Values are means \pm S.E.M. for 4 rats in each group. ${ }^{\star} P<0.05$ compared with vehicle. 
Effects of PBN lesion on pancreatic protein secretion in conscious rats

In five of nine rats, the neurotoxin ibotenic acid caused well-placed, bilaterally symmetrical lesions of the LPBN. Depictions of lesion damage in LPBN are shown in Fig. 9. The locus and extent of the lesions were determined by the

A
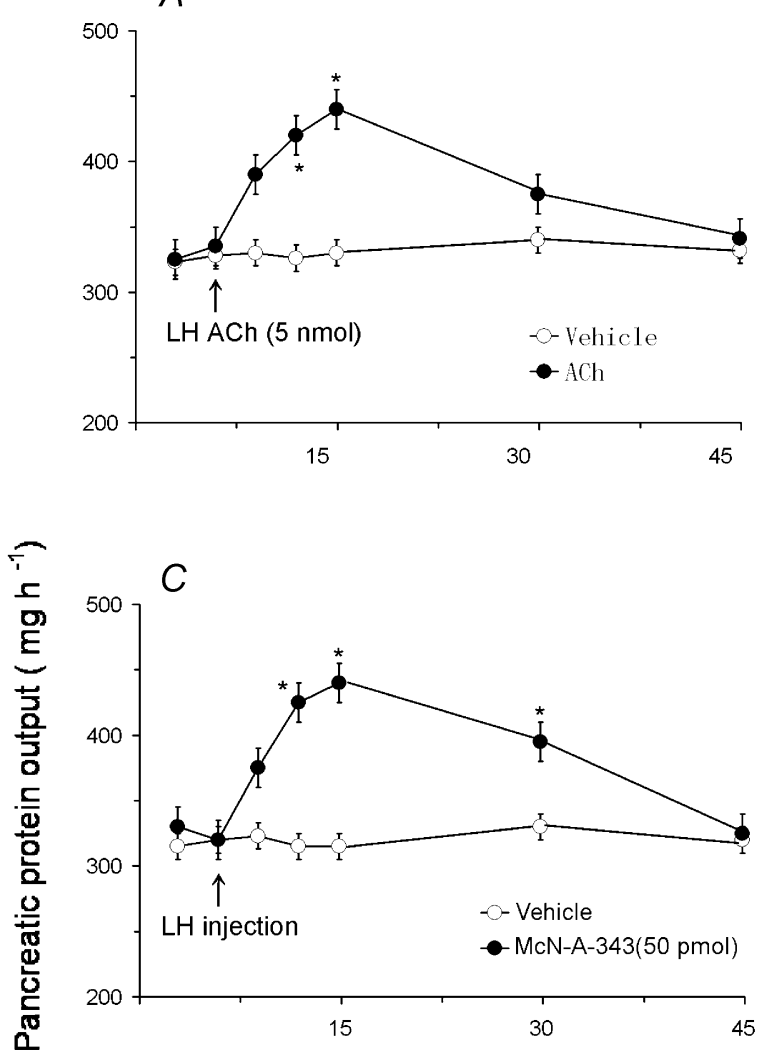

$E$

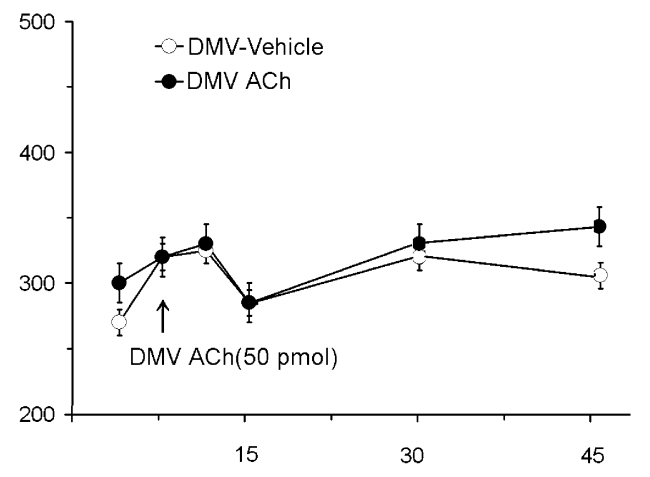

loss of neurons and the presence of gliosis. The lesions included the central, external, and to a lesser extent, the dorsal and medial subnuclei of the LPBN (Fulwiler \& Saper, 1984). In two of the four remaining rats, the lesion extended far enough ventrally to cause significant unilateral damage to the MPBN. Of the remaining two

$B$
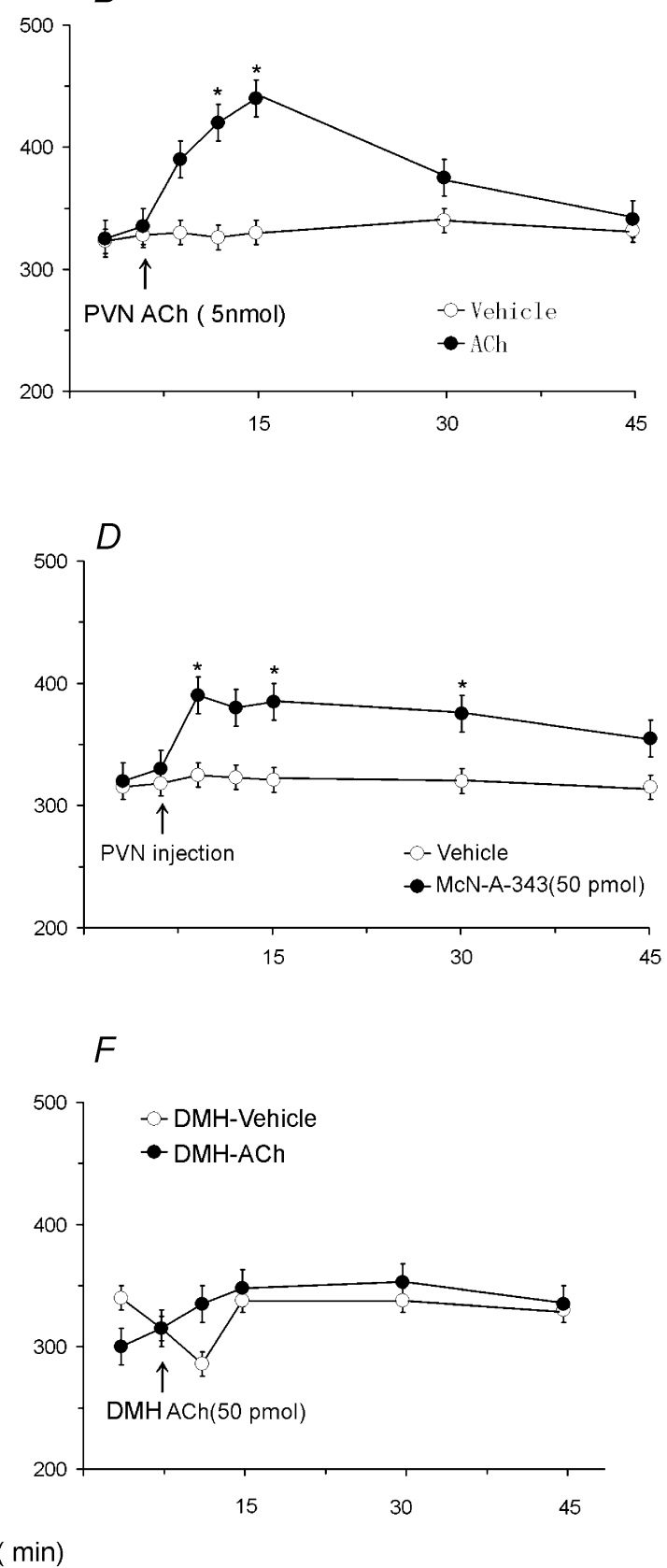

Figure 5. Effects of microinjection of $A C h$ and muscarinic $M_{1}$ receptor agonist McN-A-343 into the lateral hypothalamic nucleus, paraventricular nucleus, dorsomedial hypothalamic nucleus, or dorsal motor nucleus of the vagus on pancreatic secretion in conscious rats

Microinjection of ACh (5 pmol) into the lateral hypothalamic nucleus (LH) $(A)(n=5)$ or the paraventricular nucleus $(\mathrm{PVN})(B)(n=4)$ induced a marked increase in protein secretion. Similar results were obtained after microinjection of McN-A-343 into the LH $(C)$ or the PVN $(D)$. In contrast, microinjection of ACh at doses of 5 pmol or 50 pmol into the dorsal motor nucleus of the vagus (DMV) (E) $(n=4)$ or the dorsomedial hypothalamic nucleus $(\mathrm{DMH})(F)(n=4)$ had no effect on pancreatic secretion. Values are means \pm S.E.M. for 4 rats in each group. ${ }^{\star} P<0.05$ compared with basal. 
rats, one had incomplete damage to the external lateral subnucleus on both sides, and the other was in poor health. Functional data from these four rats were excluded from statistical analyses. In four of six MPBN-lesioned rats, the ibotenic acid infusions produced well-placed lesions located in the gustatory area of the PBN. In two rats, damage to the gustatory area on both sides was incomplete. Accordingly, data from these rats were excluded from functional analyses. Neither MPBN nor LPBN lesions significantly affected basal pancreatic secretion in the conscious rat (Fig. 10A). MPBN lesion also had no effect on pancreatic protein output stimulated by duodenal perfusion of peptone. However, LPBN ibotenic acid lesion caused a reduction in pancreatic protein secretion stimulated by intraduodenal perfusion of peptone (Fig. 10A). The cumulative net increase in protein output was decreased from the control rate of $102 \mathrm{mg}(30 \mathrm{~min})^{-1}$ to $64 \mathrm{mg}(30 \mathrm{~min})^{-1}$ (Fig. 10B).

\section{Effects of microinjection of glutamate into the LS and LPBN on pancreatic vagal efferent nerve activity and pancreatic protein secretion in anaesthetized rats}

We used glutamate as an agent for chemical stimulation. This agent only activates the cell bodies without activating the passing fibres. The vagal pancreatic efferent nerve displayed low spontaneous activity. Microinjection of saline had no effect on pancreatic nerve firings (Fig. 11A). Microinjection of glutamate $(30 \mathrm{nmol})$ into the LPBN produced a marked increase in pancreatic nerve firings (Fig. $11 B$ ) from a basal level of $0 \pm 0.5$ impulses $(30 \mathrm{~s})^{-1}$ to $14 \pm 2$ impulses $(30 s)^{-1}$ in five rats tested. The response reached a plateau $1 \mathrm{~min}$ after injection, and gradually returned to baseline after $10 \mathrm{~min}$. The distribution of cannula placements in LPBN is shown in Fig 11E. Injection into the LPBN was histologically confirmed in five of six rats used in this study. LPBN injection sites were centred in the central lateral and dorsal lateral portions of the LPBN (Fulwiler \& Saper, 1984). Injection reaching the ventral lateral and external lateral portions were observed in some rats; data from these rats were included in the analysis. In one rat, the injection sites were located in the mesencephalic nucleus and in the MBPN (Fig. 11E). Glutamate injection had no effect on pancreatic nerve firing in these rats.

In a separate study, injection into the LS was histologically confirmed in all six rats. The LS injection sites were found in both the rostral and caudal part of the lateral septal nucleus. Microinjection of glutamate $(30 \mathrm{nmol})$ into the LS produced a mild increase in vagal pancreatic efferent firings from a basal level of $0 \pm 0.5$ impulses $(30 \mathrm{~s})^{-1}$ to $4 \pm 0.5$ impulses $(30 \mathrm{~s})^{-1}$.

Given the fact that ACh did not act on DMV neurons to stimulate pancreatic secretion, we tested the hypothesis that ACh released from the LPBN activates neurons of the hypothalamus, which in turn stimulates pancreatic preganglionic motor neurons, and increases vagal efferent activities. We showed that microinjection of $5 \mathrm{nmol}$ MSCP into the PVN significantly inhibited pancreatic nerve firings evoked by LPBN injection of glutamate (Fig. 11C). After pancreatic nerve recording studies, the same anaesthetized rats were subjected to a pancreatic
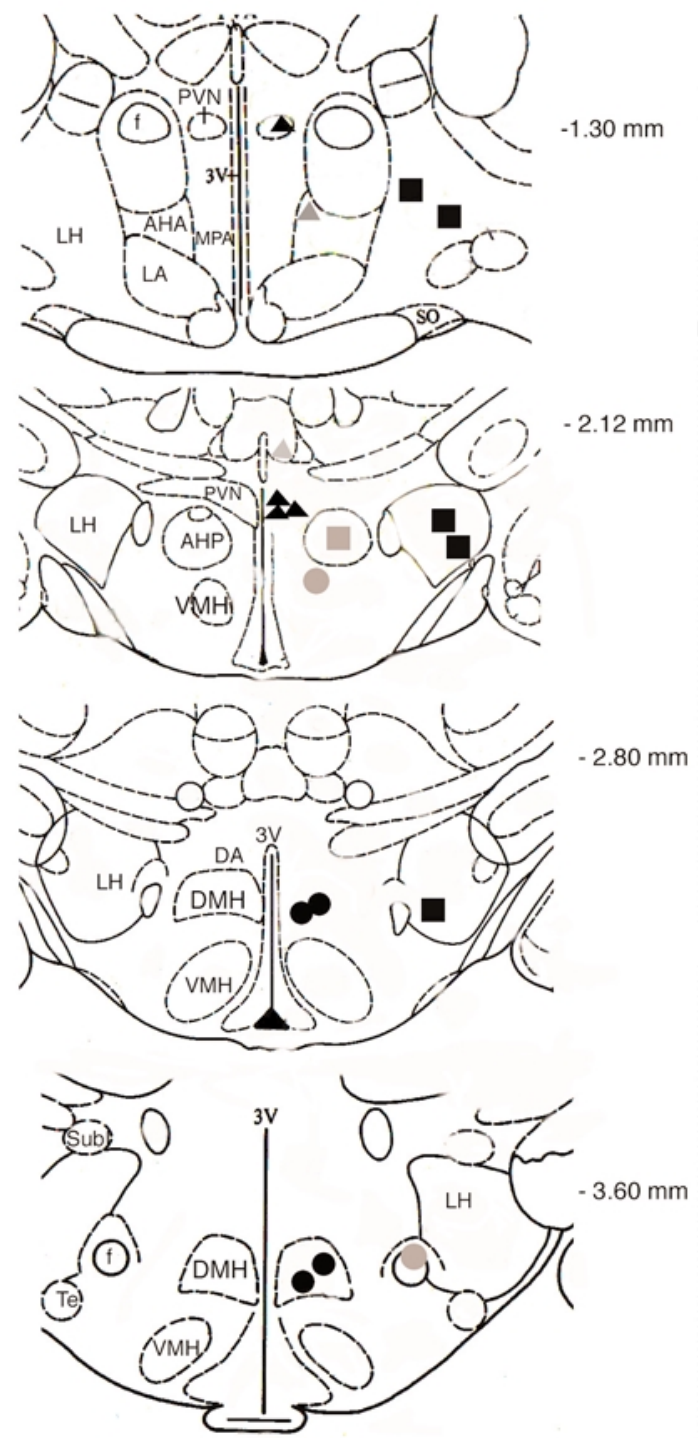

\section{Figure 6. Location of microinjection sites of ACh in the} hypothalamus

Coronal sections adapted from the atlas of the rat brain by Paxinos \& Watson (1998) showing the ACh microinjection sites in the hypothalamus. Numbers to the right of each section indicate the distance from the bregma. Black circles, squares, and triangles indicate the sites within the dorsomedial hypothalamic nucleus $(\mathrm{DMH})$, lateral hypothalamic nucleus ( $\mathrm{LH})$, and periventricular hypothalamic nucleus (PVN), respectively. The grey symbols indicate injection sites outside these target nuclei. AHP, anterior hypothalamic area (posterior); $\mathrm{VMH}$, ventromedial hypothalamic nucleus; MPA, medial oreoptic area; DMH, dorsomedial hypothalamic nucleus; DA, dorsal hypothalamus area; Te, terete nucleus. 

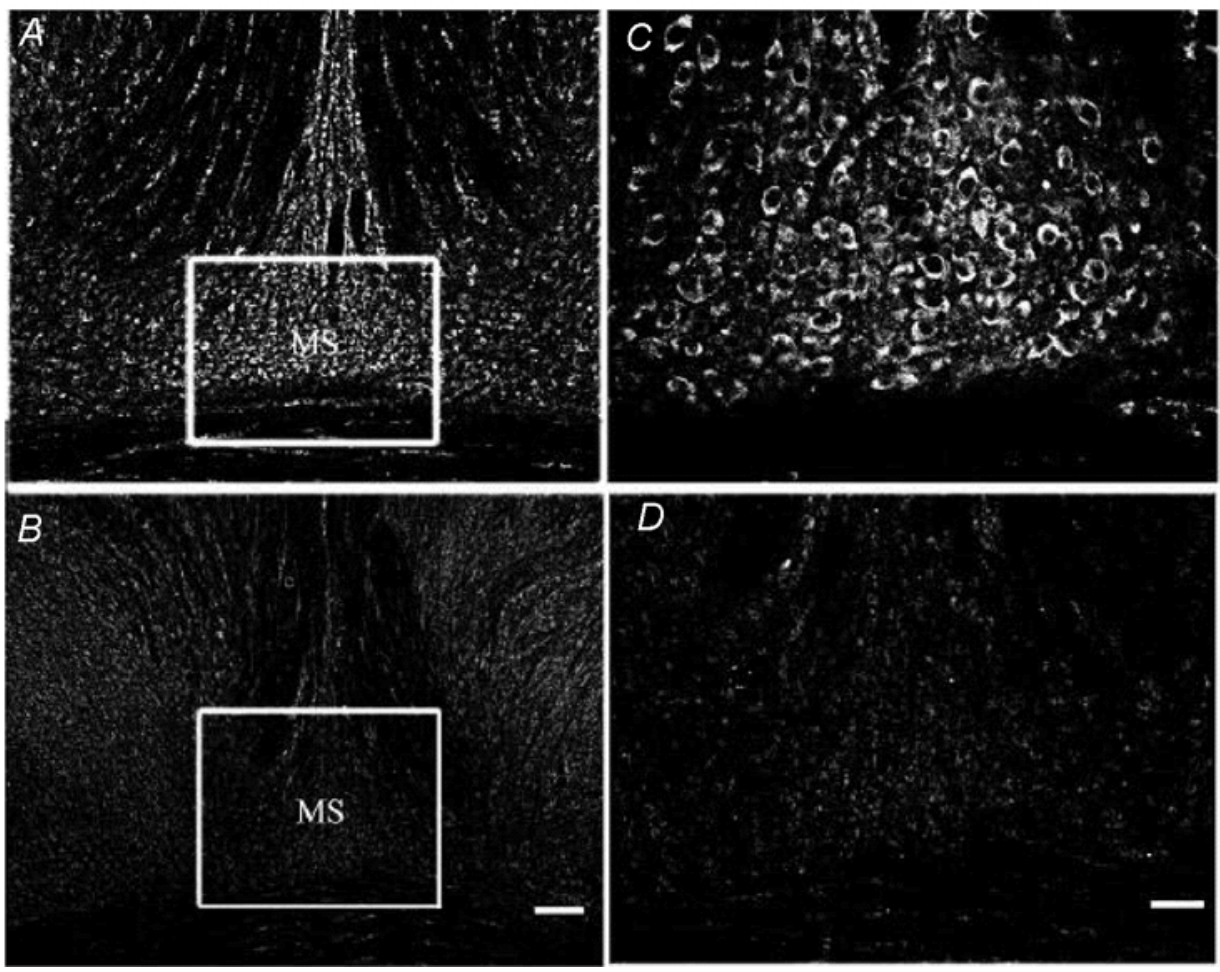

Figure 7. Effect of $192 \mathrm{lgG}$-saporin on choline acetyltransferase-immunopositive neurons in the medial septum

$A$, choline acetyltransferase (ChAT)-immunopositive neurons in a section of the medial septum (MS) from sham-operated control rats. $B$, fewer ChAT-positive neurons are visible in a section of the MS region after injection of 192 IgG-saporin. $C$ and $D$, higher magnification of images depicted in $A$ and $B$, respectively. Scale bar $B=0.25 \mathrm{~mm} ; D=0.125 \mathrm{~mm}$.

$A$

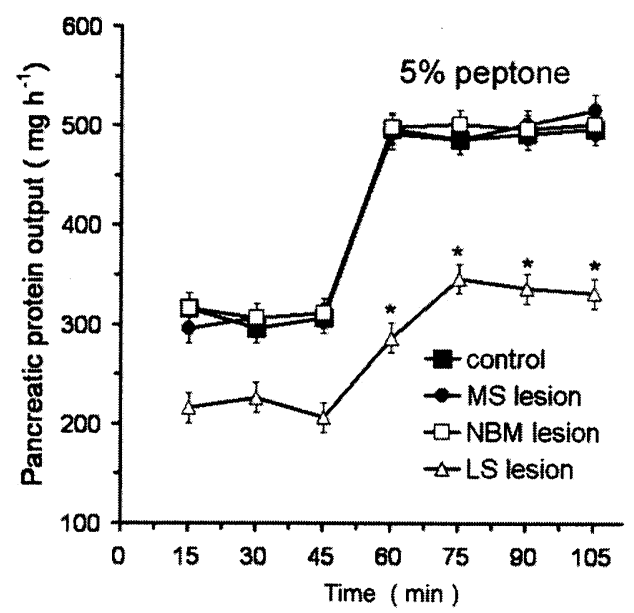

$B$

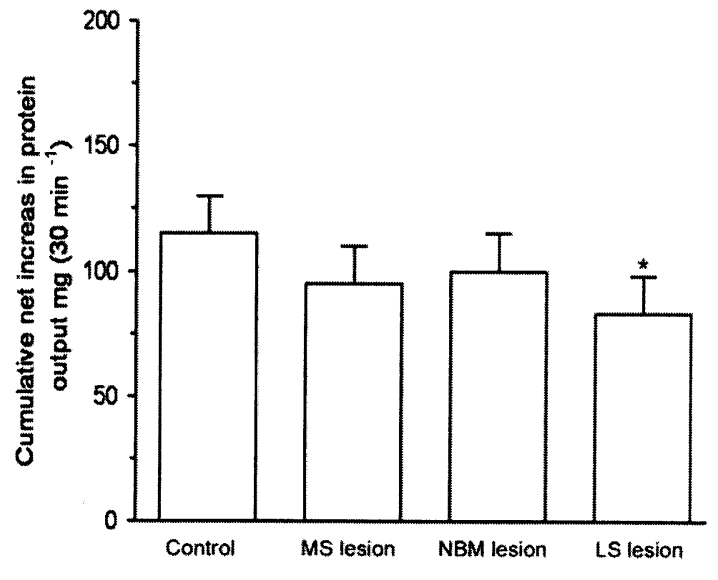

Figure 8. Effects of selective lesion of basal forebrain cholinergic neurons on pancreatic secretion in conscious rats

The selective cholinergic toxin 192 IgG-saporin was used to lesion the neurons of the medial septum (MS), the lateral septum (LS), and the nucleus basalis magnocellularis (NBM). A, time course of peptone-induced pancreatic secretion in control rats and in rats with lesions. MS or NBM lesions had no effect on basal pancreatic output, nor did they affect pancreatic protein secretion stimulated by luminal perfusion of peptone. In contrast, LS lesion resulted in a significant decrease in basal pancreatic output from $310 \pm 7$ to $212 \pm 7 \mathrm{mg} \mathrm{h}^{-1}$, and a reduction in the cumulative net increase in protein output evoked by peptone from $118 \pm 6$ to $80 \pm 4 \mathrm{mg}(30 \mathrm{~min})^{-1}(B)$, suggesting that cholinergic LS neurons play a role in regulating basal and stimulated pancreatic secretion. Values are means \pm S.E.M. for 4 rats in each group. ${ }^{\star} P<0.05$ compared with basal levels in $A$, and compared with control in $B$. 
A

$B$
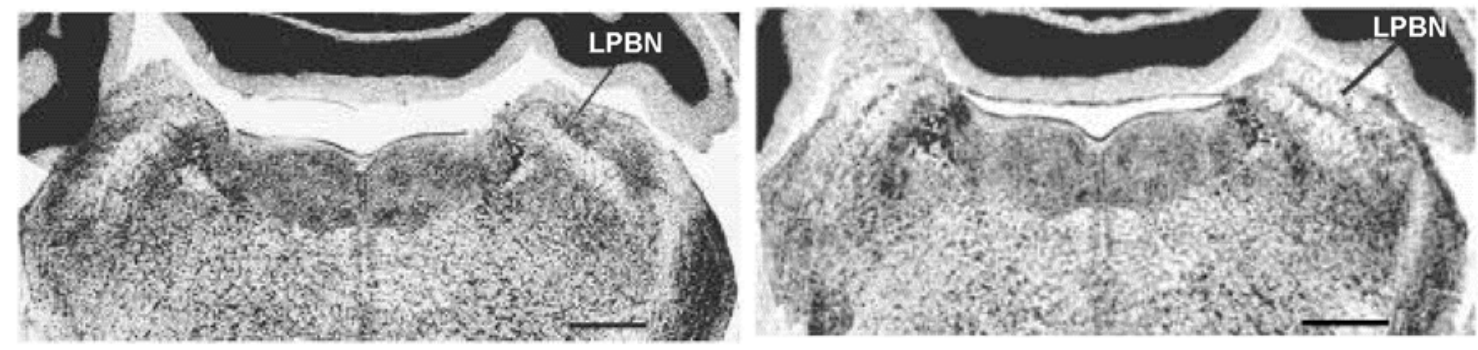

C

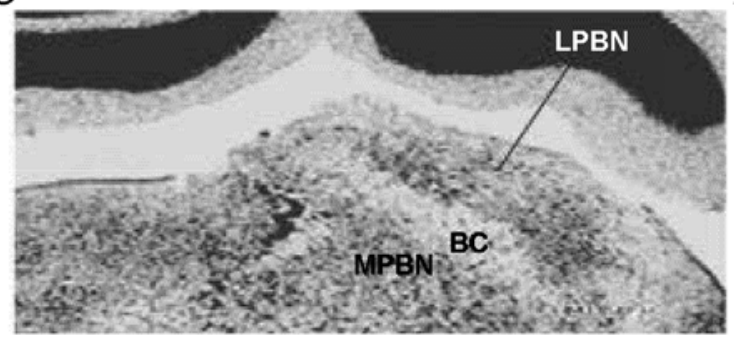

$D$

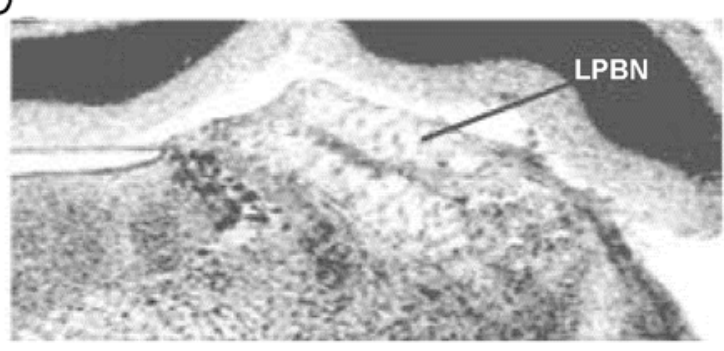

\section{Figure 9. Coronal sections through the dorsal pons}

$A$, coronal section from a rat that received a PBS injection into the lateral parabrachial nucleus (LPBN). $B$, coronal section after a well-placed injection of ibotenic acid into the LPBN. Scale bar $=0.8 \mathrm{~mm}$. $C$ and $D$, higher magnification of images depicted in $A$ and $B$, respectively. Sections were stained with cresyl violet. MPBN, medial parabrachial nucleus; $B C$, brachium conjuctivum.

protein secretion study. Microinjection of glutamate into the LPBN resulted in a correlated increase of pancreatic protein output from a basal level of $123 \pm 5 \mathrm{mg} \mathrm{h}^{-1}$ to $226 \pm 11 \mathrm{mg} \mathrm{h}^{-1}$. PVN pretreatment with MSCP $(5.0 \mathrm{nmol})$ eliminated pancreatic protein secretion evoked by LPBN injection of glutamate (Fig. 11D).

\section{DISCUSSION}

Exocrine pancreatic secretion is largely controlled by the autonomic nervous system. We and other investigators have clearly demonstrated that the vago-vagal reflex plays a crucial role in the mediation of postprandial pancreatic
$A$

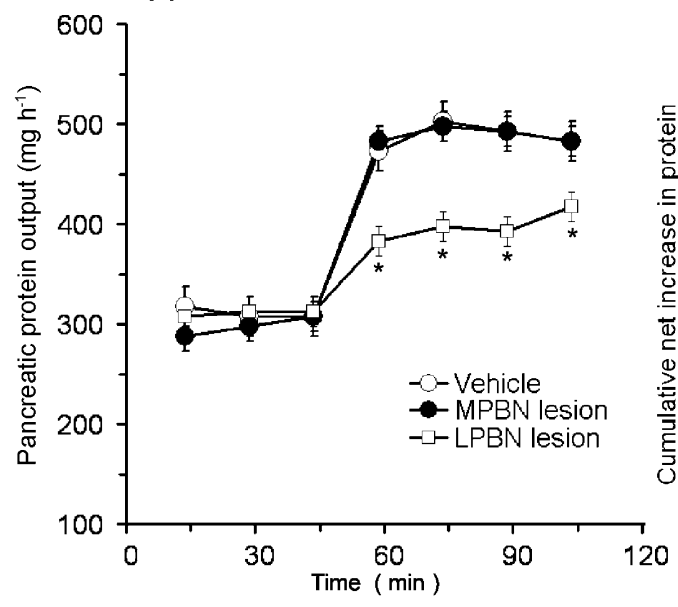

$B$

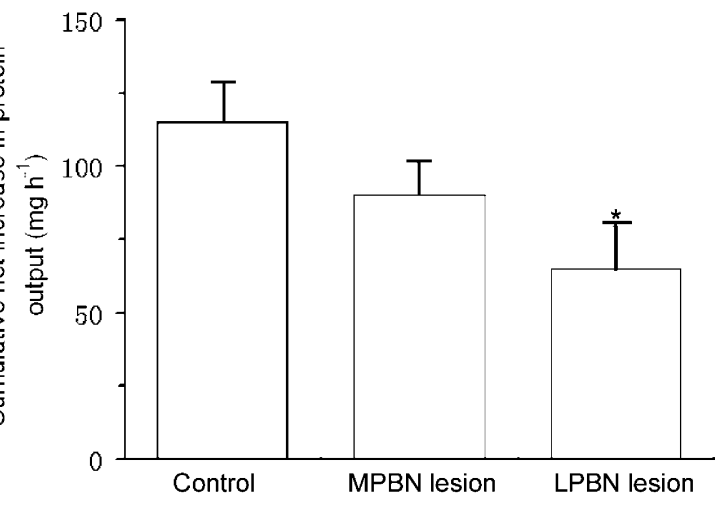

Figure 10. Effects of lateral or medial parabrachial nucleus lesions induced by ibotenic acid on pancreatic secretion in conscious rats

$A$, time course of peptone-stimulated pancreatic secretion in control rats and in rats with lateral parabrachial nucleus (LPBN) or medial PBN (MPBN) lesions. $B$, cumulative net increases in protein output stimulated by peptone. Ibotenic acid treatment had no effect on basal pancreatic secretion. Lateral parabrachial nucleus (LPBN) lesion significantly reduced pancreatic protein secretion in response to intraduodenal perfusion of peptone, suggesting that LPBN neurons are involved in mediating pancreatic secretion evoked by the vagovagal reflex. Values are means \pm s.E.M. for 4 rats with MPBN lesion and 5 rats with LPBN lesion. ${ }^{*} P<0.05$ compared with basal in $A$ and with control in $B$. 
$A$

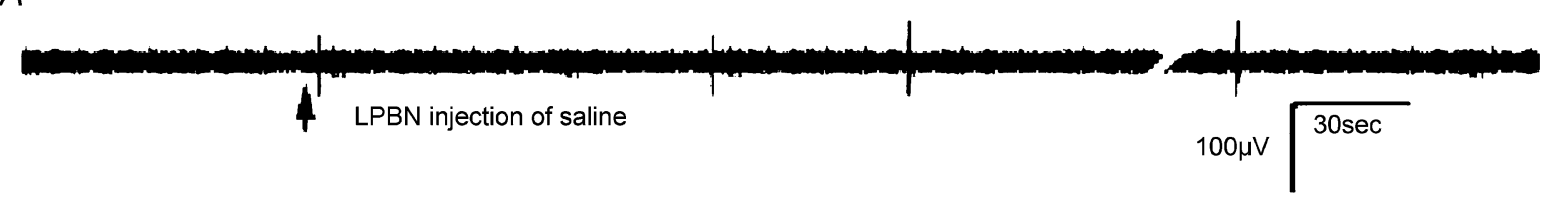

B

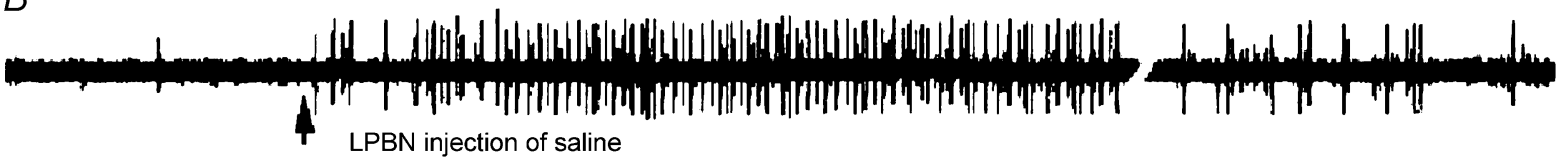

C

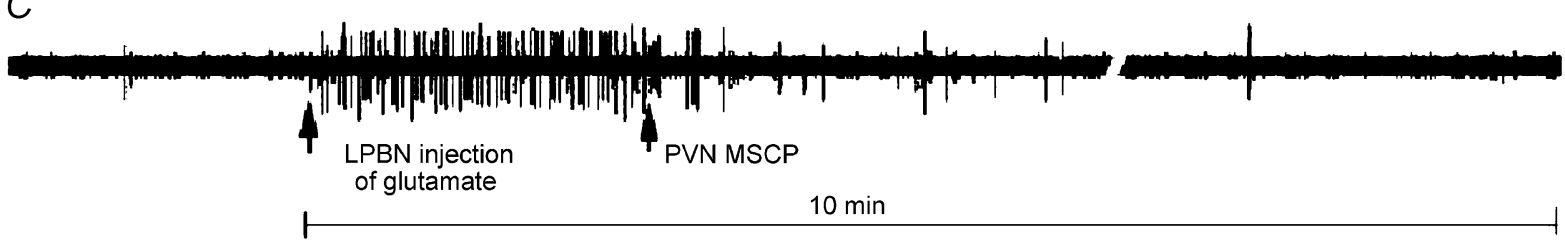

D

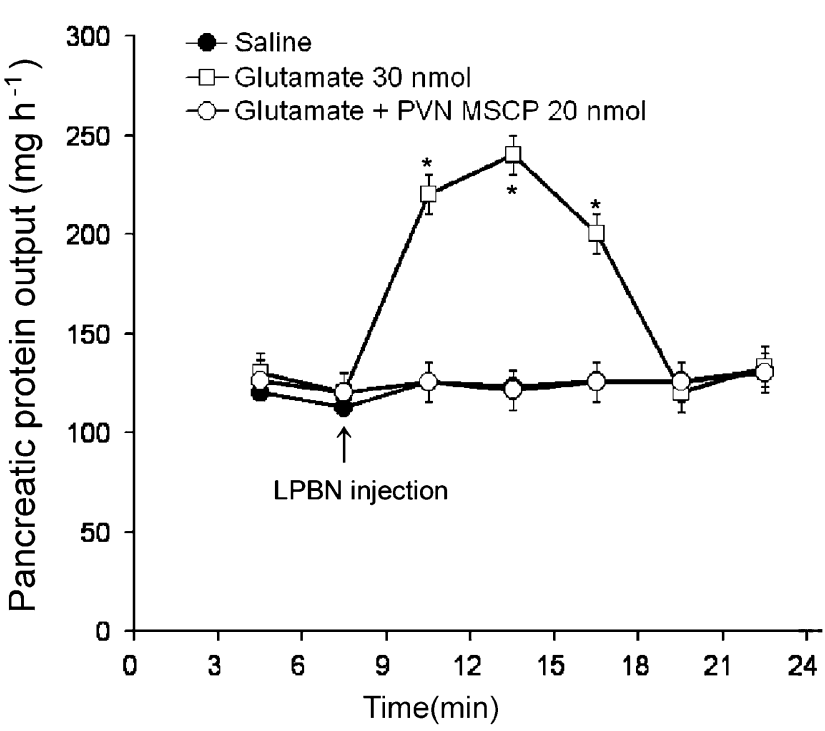

$E$
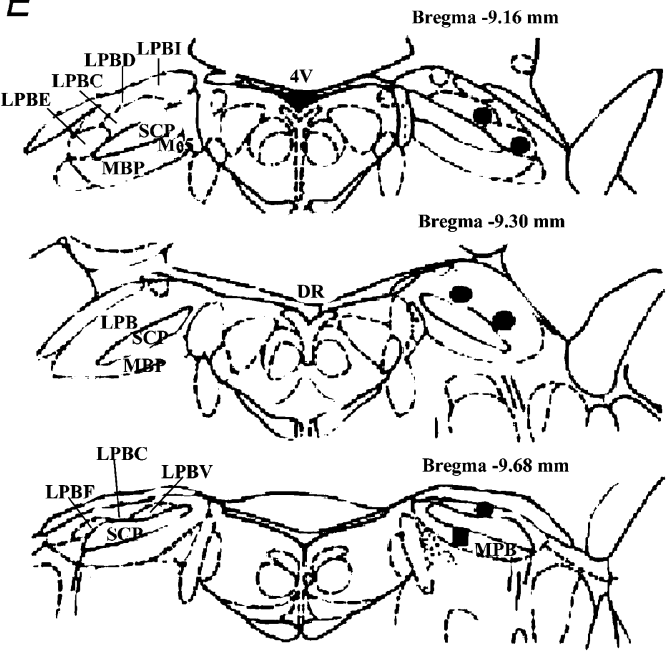

Bregma $-9.80 \mathrm{~mm}$

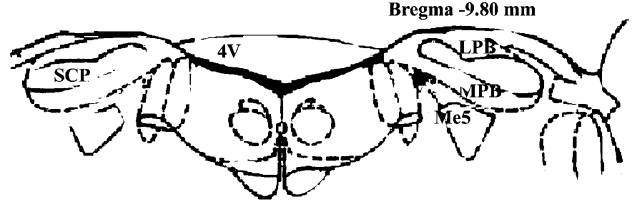

Figure 11. Responses of the vagal pancreatic efferent nerve to microinjection of glutamate into the lateral parabrachial nucleus, and the correlated pancreatic protein secretion in the anaesthetized rat

Original action potentials are presented. $A$, vagal pancreatic efferent nerve displayed low spontaneous activity. Microinjection of saline had no effect on pancreatic nerve firings. $B$, microinjection of glutamate $(30 \mathrm{nmol})$ into the lateral parabrachial nucleus (LPBN) produced a marked increase in pancreatic nerve firings. The response reached a plateau $1 \mathrm{~min}$ after injection, and gradually returned to baseline after $10 \mathrm{~min}$. $C$, methscopolamine (MSCP, $5 \mathrm{nmol}$ ) injection into the periventricular hypothalamic nucleus (PVN) abolished pancreatic nerve firings evoked by the LPBN injection of glutamate. $D$, glutamate microinjection induced a correlated increase of pancreatic protein output in the anaesthetized rats. Pretreatment with MSCP abolished pancreatic protein secretion evoked by LPBN injection of glutamate. Values are means \pm S.E.M. for 5 rats. ${ }^{\star} P<0.05$ compared with basal. $E$, coronal sections of the rat brain adapted from the atlas of the rat brain by Paxinos \& Watson (1998) showing the sites of glutamate microinjection in the parabrachial nuclei. Black circles indicate injection sites within the LPBN; black squares indicate sites in the medial parabrachial nucleus (MPBN) or the mesencephalic trigeminal tract (Me5). LPBC, lateral parabrachial nucleus central; LPBD, lateral parabrachial nucleus central, dorsal; LPBE, lateral parabrachial nucleus central, external; LPBI, lateral parabrachial nucleus, internal; $4 \mathrm{~V}$, 4th ventricle; MBP, medial parabrachial nucleus; SCP, superior cerebellar peduncle; DR, dorsal raphe nucleus. 
enzyme secretion. Previous studies in the rat have also shown that CCK (Li \& Owyang, 1993b, 1994; Li et al. 1997) and luminal non-CCK-dependent factors (Li \& Owyang, 1996a) such as osmolality, disaccharides, and mechanical stimulation evoke pancreatic secretion via intestinal vagal mucosal afferent fibres. We have demonstrated that 5-HT released from intestinal enterochromaffin cells stimulates both firing of vagal primary afferent neurons and pancreatic secretion evoked by luminal non-CCKdependent factors (Li \& Owyang, 1996a; Li et al. 2000; Zhu et al. 2001). Although pancreatic secretion can be mediated by vago-vagal reflexes located within the brainstem, these reflexes may be modulated by input from higher centres (Rogers et al. 1996). CNS control over the cephalic phase of pancreatic secretion has been recognized to be considerable since Pavlov's time (Pavlov, 1910; Sarles et al. 1968). Microinjection of thyrotropin-releasing hormone or PP into the DMV has been shown to stimulate or inhibit pancreatic secretion (Okumura et al. 1995a,b). We have demonstrated that calcitonin gene-related peptide and somatostatin inhibit pancreatic secretion at a central vagal site (Li et al. 1998; Li \& Owyang, 1993a). The physiological importance of input from the forebrain on postprandial pancreatic secretion, however, remains largely unknown.

The hypothalamus plays a vital role in the processing and integration of neurohumoral information arising from the viscera. Gilsdorf et al. (1966) reported that electrical stimulation of the ventromedial anterior hypothalamus of conscious dogs induced an increase, whereas activation of the posterior hypothalamus caused a decrease, in pancreatic secretion. Mine et al. (1985) discovered that electrolytic lesions of various nuclei in the amygdaloid body in the rat affected pancreatic secretion in different ways. To investigate the role of the forebrain in pancreatic secretion, we conducted pancreatic secretion studies using unanaesthetized chronic decerebrate rats that had survived transection for an average of 14 days, a classical method of removing forebrain influence. We showed that chronic decerebrate rats are capable of retaining about $65 \%$ of basal pancreatic protein output, and about $60 \%$ of pancreatic protein secretion stimulated by luminal perfusion of peptone. These observations clearly indicate that the caudal brainstem contains the neural network sufficient to mediate the major part of basal pancreatic tone and protein secretion stimulated by luminal agents. However, the forebrain also plays an important role in modulating the vago-vagal reflex in the brainstem.

Peripheral cholinergic blockade completely abolishes pancreatic secretion evoked by CCK and non-CCKdependent luminal factors (Li \& Owyang, 1993b, 1994, 1996a,b; Li et al. 1997, 2000). However, the site(s) of action of peripherally administrated atropine is not clear.
Choline acetyltransferase immunoreactivity is abundant in the nodose ganglia and the CNS; for example, in the DMV, septal nuclei, PBN, bed nucleus, amygdala, and hypothalamus (Quirion \& Boksa, 1986; Portillo et al. 1996). Previous studies have shown that the central cholinergic pathway contributes significantly to the regulation of digestive functions including salivation (Tomic-Beleslin \& Beleslin, 1986), gastric secretion (Grill \& Norgren, 1978), gastric dysrhythmias (Hasler et al. 1995), emesis (Pedigo \& Brizzee, 1985), and the oesophagomotor response (Lu \& Bieger, 1998). In the current study, we showed that in conscious rats, I.C.V. infusion of MSCP, a blood-brain barrier-impermeant cholinergic muscarinic receptor antagonist significantly decreased basal pancreatic protein output and reduced pancreatic protein output stimulated by peptone and $\mathrm{NaCl}$, supporting the importance of the central cholinergic pathway in the mediation of basal and pancreatic secretion stimulated by luminal agents.

Surgical decerebration interrupts the entire descending neural input to the brainstem. MSCP infused into the lateral cerebral ventricle may flow into the third and fourth ventricle and act on the vagal nuclei in the brainstem. In this study, we demonstrated that MSCP microinjection into the LH produced inhibitory effects similar to those observed with surgical decerebration. Microinjection of ACh into the LH or PVN stimulated pancreatic secretion. However, injection of the same or higher doses of ACh into the DMV did not affect pancreatic secretion. We have shown that, in contrast to $\mathrm{ACh}$, microinjection of neuropeptide $\mathrm{Y}$ or substance $\mathrm{P}$ into the DMV markedly increased pancreatic efferent nerve firings (Wu et al. 2002). These observations suggest that the central cholinergic pathway appears to function at the hypothalamus rather than at medullary preganglionic motor neurons.

Viral retrograde transneuronal labelling has been used to show that CNS cell groups project to the pancreatic parasympathetic neurons (Loewy \& Haxhiu, 1993). Labelled neurons were evident in the PVN as well as in the LH nucleus. The dorsal hypothalamic nuclei also contained labelled neurons. A few labelled cells were found in the peripheral $\mathrm{DMH}$, but none in the ventromedial hypothalamic nucleus. The DMH plays an important role in the control of feeding, drinking, and body weight (Bellinger \& Bernardis, 2002). Our studies, however, showed that microinjection of ACh into the DMH had no significant effect on pancreatic protein output.

To investigate the role of endogenous ACh in the CNS on basal and luminally stimulated pancreatic protein secretion, the rats were pretreated with hemicholinium-3, which selectively inhibits the high-affinity choline uptake system and demonstrates specific binding to the cholinergic regions of the rat brain (Rainbow et al. 1984), 
apparently at presynaptic terminals that release $\mathrm{ACh}$ (Quirion, 1985). The dose of hemicholinium-3 used in this study caused maximum depletion of brain ACh in spontaneous hypertensive rats (Brezenoff \& Rusin, 1974; Freeman et al. 1979). I.c.v. injection of hemicholinium-3 evoked a selective depressor response in unanaesthetized spontaneous hypertensive rats, but not in normotensive controls (Brezenoff \& Caputi, 1980). In the present study, we showed that $15 \mathrm{~min}$ after the injection of hemicholinium-3 into the lateral cerebral ventricle, basal pancreatic protein output was significantly decreased. This treatment also produced partial inhibition of pancreatic secretion stimulated by intraduodenal perfusion of $5 \%$ peptone and 600 mosmol $^{-1} \mathrm{NaCl}$. These observations suggest that tonic cholinergic neurotransmission in the hypothalamus regulates basal pancreatic tone and cholinergic mechanisms are involved in modulating pancreatic secretion stimulated via the vago-vagal reflex.

Autoradiographic studies have shown that dense areas of muscarinic receptor binding sites occur throughout the CNS, including the hypothalamus (Quirion \& Boksa, 1986). The role of central muscarinic receptors in pancreatic enzyme secretion has not been investigated. The present study demonstrates that direct stimulation of the hypothalamus by ACh causes an increase in pancreatic secretion in conscious rats. Furthermore, microinjection of the muscarinic $\mathrm{M}_{1}$ receptor specific agonist, $\mathrm{McN}$ A-343 (de Vries et al. 2001), produces a $40 \%$ increase in pancreatic secretion, suggesting that the $\mathrm{M}_{1}$ receptor in the CNS is involved in the ACh-induced pancreatic secretion.

Efferent parasympathetic output originates from the DMV. The hypothalamus has direct descending projections to the dorsal vagal complex. Fluorescent tracer labelling studies have shown that that hypothalamobular neurons projecting to the DMV are most abundant in the ventral, medial and lateral parts of the PVN (Portillo et al. 1996). Electrophysiological studies have shown that the hypothalamus plays an important role in the regulation of the dorsal vagal complex. Stimulation of the LH excites DMV neurons (Nishimura \& Oomura, 1987) and increases the activity of the axons in the hepatic branch of the vagus (Yoshimatsu et al. 1988). Stimulation of the PVN was shown to cause an increase in the spontaneous activity of $59 \%$ of PVN-sensitive DMV neurons and to cause a decrease in the basal activity of $66 \%$ of cells of the nucleus of the solitary tract (Zhang et al. 1999). We recently studied the DMV neural circuitry responsible for vagal efferent signalling to the pancreas. We showed that neuropeptide $\mathrm{Y}$ and substance $\mathrm{P}$ stimulated, while somatostatin inhibited, pancreatic DMV preganglionic neurons (Wu et al. 2001). Retrograde transneuronal viral tracing studies provided strong anatomical evidence that hypothalamic neurons project to the pancreas. After injection of Bartha pseudorabies virus into the rat pancreas, labelled transneuronal cell bodies were seen in four hypothalamic nuclei: PVN, LH, and the dorsal and dorsomedial hypothalamic nuclei (Jansen et al. 1997). PVN labelling was restricted to the parvicellular subnuclei. Within the LH area, infected neurons were found in the perifornical area and in the caudal area at the level of the subthalamic nuclei. These anatomical observations support our current findings, and suggest that under physiological conditions, the hypothalamic cholinergic system may tonically stimulate preganglionic DMV neurons projecting to the pancreas.

Cholinergic cell bodies are distributed throughout the brain, and cholinergic axons innervate most regions of the CNS. There are two major sources of cholinergic neurons in the basal forebrain, the septal nuclei and the nucleus basalis of Meynert (Butcher \& Woolf, 1984; Kimura et al. 1984), which project to the cortex, hippocampus, amygdala, thalamus and brainstem (Butcher \& Woolf, 1984).

The LS is a large cell mass located in the rostrodorsal septal region. Study of the connections of the rat lateral septal complex has demonstrated that this nucleus receives major descending input from the hippocampal formation, which converges with ascending input from many parts of the hypothalamus and brainstem. LS projections are known to innervate the hypothalamus (Risold \& Swanson, 1997). Electrophysiological recordings have shown that LS stimulation evokes an increase in the excitability of rat hypothalamic neurons (Blume et al. 1982; Kendrick, 1983). Ablation of the lateral septum with ibotenate decreased choline acetyltransferase concentrations in the PVN, suggesting that cholinergic innervation of these areas is septal in origin (Oorjitham et al. 1989). The NBM, which is analogous to the nucleus basalis of Meynert in humans, is another source of cholinergic neurons in the rat basal forebrain. Many cholinergic neurons in the basal forebrain express high levels of the low-affinity p75 NGFr (Gage et al. 1989). When $192 \mathrm{IgG}$, the monoclonal antibody to p75 NGFr, is coupled to the ribosomalinactivating protein saporin, it selectively destroys neurons bearing NGFr in in vivo rats (Book et al. 1992; Wiley, 1992). It has been reported that a septal injection of this immunotoxin selectively destroys cholinergic cells but spares NGFr-negative noncholinergic neurons within the basal forebrain (Wenk et al. 1994; Lee et al. 1994). In the current study, we performed a series of experiments to identify the sites of cholinergic neurons that are responsible for the modulation of basal and stimulated pancreatic secretion. We showed that MS or NBM cholinergic neuronal lesions had no effect on either basal pancreatic protein secretion or pancreatic protein secretion stimulated by intraduodenal perfusion of peptone. In contrast, lesion of the LS resulted in a decrease of basal 
protein output, and a $30 \%$ reduction of the cumulative net increase in protein output stimulated by peptone.

There is another conspicuous zone of cholinergic neurons in the lateral tegmental area of the rostral rhombencephalon (Butcher \& Woolf, 1984; Kimura et al. 1984; Rye et al. 1987), including the pedunculopontine (e.g. parabrachial nucleus) and laterodorsal tegmental nuclei. The PBN sends direct input to the hypothalamic nuclei, including the LH and PVN (Saper \& Loewy, 1980; Fulwiler \& Saper, 1984). This anatomical evidence raises the possibility that the pontine nuclei may be involved in the activation of the LH and PVN via cholinergic pathways. Further, it is possible that afferent inputs from the gastrointestinal tract reach the LPBN. (Herbert et al. 1990). In situ hybridization autoradiography has shown that $45 \mathrm{~min}$ after intragastric $\mathrm{HCl}$ challenge, many neurons in the NTS, LPBN, and hypothalamic PVN express c-fos mRNA (Michl et al. 2001). Immunohistochemical studies have shown that intestinal perfusion of dietary glucose induces c-fos expression in the NTS, area postrema, and LPBN (Wang et al. 1999). More recently, neurophysiological recording studies have suggested that oral and gastrointestinal sensory signals converge to activate the neurons in the LPBN (Karimnamazi et al. 2002). In the present study, we showed that neither MPBN lesion nor LPBN lesion had a significant effect on basal pancreatic secretion in the conscious rat. Further, MPBN lesion did not affect pancreatic protein output stimulated by duodenal perfusion of peptone. LPBN ibotenic acid lesion, in contrast, inhibited peptoneinduced pancreatic protein by $40 \%$. Electrophysiological studies showed that microinjection of glutamate into the LS and the LPBN stimulated vagal pancreatic efferent nerve firing, and these responses were blocked by microinjection of a cholinergic antagonist into the PVN. Considered together, these observations suggest that cholinergic neurons in the LS are responsible for maintaining pancreatic tone. These neurons also are involved in modulating stimulated pancreatic secretion. LPBN cholinergic input to the hypothalamus plays a major role in the modulation of vagal pancreatic efferent nerve activity and pancreatic protein secretion stimulated by the vago-vagal reflex.

\section{REFERENCES}

Bellinger LL \& Bernardis LL (2002). The dorsomedial hypothalamic nucleus and its role in ingestive behavior and body weight regulation: lessons learned from lesioning studies. Physiol Behav 76, 431-442.

Blume HW, Pittman QJ, Lafontaine S \& Renaud LP (1982). Lateral septum-medial hypothalamic connections: an electrophysiological study in the rat. Neuroscience 7, 2783-2792.

Book AA, Wiley RG \& Schweitzer JB (1992). Specificity of 192 IgGsaporin for NGF receptor-positive cholinergic basal forebrain neurons in the rat. Brain Res 590, 350-355.
Brezenoff HE \& Caputi AP (1980). Intracerebroventricular injection of hemicholinium-3 lowers blood pressure in conscious spontaneously hypertensive rats but not in normotensive rats. Life Sci 26, 1037-1045.

Brezenoff HE \& Rusin J (1974). Brain acetylcholine mediates the hypertensive response to physostigmine in the rat. Eur J Pharmacol 29, 262-266.

Butcher LL \& Woolf NJ (1984). Histochemical distribution of acetylcholinesterase in the central nervous system: clues to the localization of cholinergic neurons. In Handbook of Chemical Neuroanatomy, ed. Björklund A, Hökfelt T \& Kuhar MJ, pp. 1-50. Elsevier, Amsterdam.

Callera JC, Bonagamba LH, Sevoz C, Laguzzi R \& Machado BH (1997). Cardiovascular effects of microinjection of low doses of serotonin into the NTS of unanesthetized rats. Am J Physiol 272, R1135-1142.

de Vries B, Roffel AF, Zaagsma J \& Meurs H (2001). Effect of fenoterol-induced constitutive beta(2)-adrenoceptor activity on contractile receptor function in airway smooth muscle. Eur J Pharmacol 431, 353-359.

DiRocco RJ \& Grill HJ (1979). The forebrain is not essential for sympathoadrenal hyperglycemic response to glucoprivation. Science 204, 1112-1114.

Freeman JJ, Macri JR, Choi RL \& Jenden DJ (1979). Studies on the behavioral and biochemical effects of hemicholinium in vivo. J Pharmacol Exp Ther 210, 91-97.

Fulwiler CE \& Saper CB (1984). Subnuclear organization of the efferent connections of the parabrachial nucleus in the rat. Brain Res 7, 229-259.

Gage FH, Batchelor P, Chen KS, Chin D, Higgins GA, Koh S, Deputy S, Rosenberg MB, Fisher W \& Björklund A (1989). NGF receptor reexpression and NGF-mediated cholinergic neuronal hypertrophy in the damaged adult neostriatum. Neuron $\mathbf{2}$, 1177-1184.

Gilsdorf RB, Pearl JM \& Leonard AS (1966). Central autonomic influences on pancreatic duct pressure and secretory rates. Surg Forum 17, 341-342.

Grill HJ \& Norgren R (1978). The taste reactivity test. II. Mimetic responses to gustatory stimuli in chronic thalamic and chronic decerebrate rats. Brain Res 143, 281-297.

Halsell CB \& Frank ME (1991). Mapping study of the parabrachial taste-responsive area for the anterior tongue in the golden hamster. J Comp Neurol 306, 708-722.

Hasler WL, Kim MS, Chey WD, Stevenson V, Stein B \& Owyang C (1995). Central cholinergic and alpha-adrenergic mediation of gastric slow wave dysrhythmias evoked during motion sickness. Am J Physiol 268, G539-547.

Heckers S, Ohtake T, Wiley RG, Lappi DA, Geula C \& Mesulam MM (1994). Complete and selective cholinergic denervation of rat neocortex and hippocampus but not amygdala by an immunotoxin against the p75 NGF receptor. J Neurosci 14, 1271-1289.

Herbert H, Moga MM \& Saper CB (1990). Connections of the parabrachial nucleus with the nucleus of the solitary tract and the medullary reticular formation in the rat. J Comp Neurol 293, 540-580.

Jansen AS, Hoffman JL \& Loewy AD (1997). CNS sites involved in sympathetic and parasympathetic control of the pancreas: a viral tracing study. Brain Res 766, 29-38.

Johnson DA, Zambon NJ \& Gibbs RB (2002). Selective lesion of cholinergic neurons in the medial septum by 192 IgG-saporin impairs learning in a delayed matching to position T-maze paradigm. Brain Res 943, 132-141. 
Karimnamazi H, Travers SP \& Travers JB (2002). Oral and gastric input to the parabrachial nucleus of the rat. Brain Res 957, 193-206.

Kendrick KM (1983). Effect of testosterone on medial preoptic/anterior hypothalamic neurone responses to stimulation of the lateral septum. Brain Res 262, 137-142.

Kimura H, McGeer PL \& Peng JH (1984). Choline acetyltransferase containing-neurons in the rat brain. In Handbook of Chemical Neuroanatomy, ed. Björklund A, Hökfelt T \& Kuhar MJ, pp. 51-67. Elsevier, Amsterdam.

Lee MG, Chrobak JJ, Sik A, Wiley RG \& Buzsaki G (1994). Hippocampal theta activity following selective lesion of the septal cholinergic system. Neuroscience 62, 1033-1047.

Li Y, Hao Y \& Owyang C (1997). High-affinity CCK-A receptors on the vagus nerve mediate CCK-stimulated pancreatic secretion in rats. Am J Physiol 273, G679-685.

Li Y, Hao Y, Zhu J \& Owyang C (2000). Serotonin released from intestinal enterochromaffin cells mediates luminal non-CCKstimulated pancreatic secretion. Gastroenterology 118, 1197-1207.

Li Y, Jiang YC \& Owyang C (1998). Central CGRP inhibits pancreatic enzyme secretion by modulation of vagal parasympathetic outflow. Am J Physiol 275, G957-963.

Li Y \& Owyang C (1993a). Somatostatin inhibits pancreatic enzyme secretion at a central vagal site. Am J Physiol 265, G251-257.

Li Y \& Owyang C (1993b). Vagal afferent pathway mediates physiological action of cholecystokinin on pancreatic enzyme secretion. J Clin Invest 92, 418-424.

Li Y \& Owyang C (1994). Endogenous cholecystokinin stimulates pancreatic enzyme secretion via vagal afferent pathway in rats. Gastroenterology 107, 525-531.

Li Y \& Owyang C (1996a). Pancreatic secretion evoked by cholecystokinin and non-cholecystokinin-dependent duodenal stimuli via vagal afferent fibers in the rat. J Physiol 494, 773-782.

Li Y \& Owyang C (1996b). Peptone stimulates CCK-releasing peptide secretion by activating intestinal submucosal cholinergic neurons. J Clin Invest 97, 1463-1470.

Li Y, Zhu JX \& Owyang C (1999). Electrical physiological evidence for high- and low-affinity vagal CCK-A receptors. Am J Physiol 277, G469-477.

Loewy AD \& Haxhiu MA (1993). CNS cell groups projecting to pancreatic parasympathetic preganglionic neurons. Brain Res 620 , 323-330.

Lu WY \& Bieger D (1998). Vagal afferent transmission in the NTS mediating reflux responses of the rat esophagus. Am J Physiol 224, R1436-1445.

Michelini LC \& Bonagamba LG (1988). Baroreceptor reflex modulation by vasopressin microinjected into the nucleus tractus solitarii of conscious rats. Hypertension 11, I75-I79.

Michl T, Jocic M, Heinemann A, Schuligoi R \& Holzer P (2001). Vagal afferent signaling of a gastric mucosal acid insult to medullary, pontine, thalamic, hypothalamic and limbic, but not cortical, nuclei of rat brain. Pain 92, 19-27.

Mine K, Tsuruta N, Nakai Y, KataokA, Y, Fujiwara M, Ueki S \& Nakagawa T (1985). Effects of small amygdaloid lesions on pancreatic exocrine secretion. Brain Res 340, 9-18.

Nishimura H \& Oomura Y (1987). Effects of hypothalamic stimulation on activity of dorsomedial medulla neurons that respond to subdiaphragmatic vagal stimulation. J Neurophysiol 58, 655-675.

Okita M, Inui A, Baba S \& Kasuga M (1997). Central cholinergic regulation of pancreatic polypeptide secretion in conscious dogs. J Endocrinol 154, 311-317.
Okumura T, Pappas TN \& Taylor IL (1995a). Pancreatic polypeptide microinjection into the dorsal motor nucleus inhibits pancreatic secretion in rats. Gastroenterology 108, 1517-1525.

Okumura T, Taylor IL \& Pappas TN (1995b). Microinjection of TRH analogue into the dorsal vagal complex stimulates pancreatic secretion in rats. Am J Physiol 269, G328-334.

Oorjitham EG, Godfrey DA, Ross CD \& Dunn JD (1989). Effect of septal ablation on choline acetyltransferase in the paraventricular nucleus. Brain Res Bull 22, 277-282.

Pavlov IP (1910). The Work of the Digestive Glands. C. Griffin and Company, London.

Paxinos G \& Watson C (1998). The Rat Brain in Stereotaxic Coordinates. Academic Press, San Diego.

Pedigo NW Jr \& Brizzee KR (1985). Muscarinic cholinergic receptors in area postrema and brainstem areas regulating emesis. Brain Res Bull 14, 169-177.

Portillo F, Carrasco M \& Vallo JJ (1996). Hypothalamic neuron projection to autonomic preganglionic levels related with glucose metabolism: a fluorescent labelling study in the rat. Neurosci Lett 210, 197-200.

Quirion R (1985). Comparative localization of putative pre- and postsynaptic markers of muscarinic cholinergic nerve terminals in rat brain. Eur J Pharmacol 111, 287-289.

Quirion R \& Boksa P (1986). Autoradiographic distribution of muscarinic $[3 \mathrm{H}]$ acetylcholine receptors in rat brain: comparison with antagonists. Eur J Pharmacol 123, 170-172.

Rainbow TC, Schwartz RD, Parsons B \& Kellar KJ (1984). Quantitative autoradiography of nicotinic $\left[{ }^{3} \mathrm{H}\right]$ acetylcholine binding sites in rat brain. Neurosci Lett 50, 193-196.

Risold PY \& Swanson LW (1997). Connections of the rat lateral septal complex. Brain Res Brain Res Rev 24, 115-195.

Rogers RC, McTigue Dm And Hermann GE (1996). Vagal control of digestion: modulation by central neural and peripheral endocrine factors. Neurosci Biobehav Rev 20, 57-66.

Ruggiero DA, Giuliano R, Anwar M, Stornetta R \& Reis DJ (1990). Anatomical substrates of cholinergic-autonomic regulation in the rat. J Comp Neurol 292, 1-53.

Rye DB, Saper CB, Lee HJ \& Wainer BH (1987). Pedunculopontine tegmental nucleus of the rat: cytoarchitecture, cytochemistry, and some extrapyramidal connections of the mesopontine tegmentum. J Comp Neurol 259, 483-528.

Saper CB \& Loewy AD (1980). Efferent connections of the parabrachial nucleus in the rat. Brain Res 197, 291-317.

Sarles H, Dani R, Prezelin G, Souville C \& Figarella C (1968). Cephalic phase of pancreatic secretion in man. Gut 9, 214-221.

Siren AL, Vonhof S \& Feuerstein G (1991). Hemodynamic defense response to thyrotropin-releasing hormone injected into medial preoptic nucleus in rats. Am J Physiol 261, R305-312.

Steiner E (1973). The gustofacial response: observation on normal and anencephalic newborn infants. Symp Oral Sens Percept 4, 254-278.

Tang PC (1955). Levels of brain stem and diencephalon controlling micturition reflux. J Neurophysiol 18, 583-595.

Taylor IL (1989). Pancreatic polypeptide family: pancreatic polypeptide, neuropeptide Y, and peptide YY. In Handbook of Physiology, ed. Rauner BB, Maklouf GM \& Schultz SG, pp. 475-543. American Physiological Society, Bethesda, MD.

Tomic-Beleslin N \& Beleslin DB (1986). Salivation mediated by central M-2 muscarinic receptors in the cat. Brain Res Bull 17, 279-281.

Wang L, Cardin S, Martinez V, Tache Y \& Lloyd KC (1999). Duodenal loading with glucose induces fos expression in rat brain: selective blockade by devazepide. Am J Physiol 277, R667-674. 
Wenk GL, Stoehr JD, Quintana G, Mobley S \& Wiley RG (1994). Behavioral, biochemical, histological, and electrophysiological effects of 192 IgG-saporin injections into the basal forebrain of rats. J Neurosci 14, 5986-5995.

Whittaker VP (1988). The cholinergic synapse. In Handbook of Experimental Pharmacology, ed. Whittaker VP, pp.125-165. Springer Verlag, New York.

Wiley RG (1992). Neural lesioning with ribosome-inactivating proteins: suicide transport and immunolesioning. Trends Neurosci 15, 285-290.

Wu XY, Zhao Y, Owyang C \& Li Y (2001). Neural circuitry in the dorsal motor nucleus of vagus modulating efferent signalling to the pancreas. Digestion 63, 260 (abstract).

Wu YX, Zhao Y, Owyang C \& Li Y (2002). Characterization of the neuronal circuitry in the dorsal motor nucleus of the vagus modulating vagal efferent signalling to the pancreas: electrophysiological and immunocytochemistry studies. Gastroenterology 122, A-37 (abstract).
Yoshimatsu H, Nijima A, Oomura Y \& Katafuchi T (1988). Lateral and ventromedial hypothalamic influences on hepatic autonomic nerve activity in the rat. Brain Res Bull 21, 239-244.

Zhang X, Fogel R \& Renehan WE (1999). Stimulation of the paraventricular nucleus modulates the activity of gut-sensitive neurons in the vagal complex. Am J Physiol 277, G79-90.

Zhu JX, Wu XY, Owyang C \& Li Y (2001). Intestinal serotonin acts as a paracrine substance to mediate vagal signal transmission evoked by luminal factors in the rat. J Physiol 530, 431-442.

\section{Acknowledgements}

The investigation was supported by National Institute of Diabetes and Digestive and Kidney Diseases Grants RO1-DK-51717 (Y. Li) and RO1-DK-48419 and P30-DK 34933 (C. Owyang), and by Michigan Life Sciences Corridor Grant 1635 (Y. Li). The authors wish to thank Dr Harry Yao for providing the technical expertise in immunocytochemistry required to prepare Figure 8. 